\title{
MODELO PARA AVALIAR A REVISTA IBEROAMERICANA DE ENGENHARIA INDUSTRIAL TENDO EM VISTA SUA GESTÃO
}

\section{MODEL TO ASSESS JOURNAL OF INDUSTRIAL ENGINEERING IBEROAMERICANA TO SUPPORT ITS MANAGEMENT}

\author{
Nara Medianeira Stefano ${ }^{1}$; Juliane Vieira de Souza ${ }^{2}$; Fabrício Kurman Merlin ${ }^{3}$; Leonardo Ensslin ${ }^{4}$; \\ Sandra Rolim Ensslin ${ }^{5}$ \\ ${ }^{1}$ Universidade Federal de Santa Catarina - UFSC - Florianópolis - Brasil \\ stefano.nara@gmail.com \\ ${ }^{2}$ Universidade Federal de Santa Catarina - UFSC - Florianópolis - Brasil \\ juliane.vieiradesouza@gmail.com \\ ${ }^{3}$ Universidade Federal de Santa Catarina - UFSC - Florianópolis - Brasil \\ merlin.fabricio@gmail.com \\ ${ }^{4}$ Universidade Federal de Santa Catarina - UFSC - Florianópolis - Brasil \\ leonardoensslin@gmail.com \\ ${ }^{5}$ Universidade Federal de Santa Catarina - UFSC - Florianópolis - Brasil \\ sensslin@gmail.com
}

\section{Resumo}

A propagação de novos títulos de periódicos científicos nas diversas áreas do conhecimento tem sido preocupação dos profissionais que se interessam pela qualidade da informação científica. Sejam autores, editores, publicadores, serviços de indexação, centros de documentação, bibliotecas $e$, de maneira especial, pesquisadores (usuários da informação). O presente trabalho na forma de estudo de caso, tem por objetivo construir conhecimento sobre os critérios julgados necessários e suficientes para ajudar a indexar a Revista Iberoamericana de Engenharia Industrial no portal de periódicos da Coordenação de Aperfeiçoamento de Pessoal de Nível Superior (CAPES) segundo a percepção da decisora. Foi realizada uma abordagem quali-quantitativa. $O$ instrumento de intervenção utilizado foi à metodologia MCDA-C que possibilitou a construção de conhecimento sobre o contexto permitindo identificar o que é importante; organizar; mensurar ordinalmente; mensurar cardinalmente; integrar os critérios e medir cardinalmente a atratividade Global. Assim, o processo disponibilizado pelo modelo permitiu a decisora compreender as consequências destas ações e ter um processo formal para sua gestão.

Palavras-chave: periódicos científicos; avaliação de desempenho; MCD-C; decisor.

\section{Introdução}

Com as constantes mudanças da sociedade, as novas exigências e demandas sociais e a expansão das tecnologias de informação e de comunicação, novos desafios se colocam em, todos os setores da sociedade. Tais acontecimentos (LÉVY, 1995) têm transformado as práticas sociais e se 
constituem, simultaneamente, em resultado desta mudança e em agente de transformação cultural, social, econômica e mesmo intelectual.

Os níveis de desenvolvimento tecnológico das tecnologias digitais possibilitam acessar um imenso número de dados, conferi-los e converte-los em informações que irão apoiar os indivíduos e as suas relações com a sociedade. É neste contexto que se inserem os periódicos científicos (PAVAN; STUMPF, 2007; MOGHADDAM; MOBALLEGHI, 2008; SALAS, 2008; SOUZA, 2010). São um dos segmentos importantes das bibliotecas e um dos recursos mais valiosos da cadeia de comunicação científica. Os pesquisadores têm tentado avaliar o uso dos periódicos científicos por meio de muitas maneiras, tais como a utilização de questionário, entrevistas, contagem de citações, entre outras. Apesar dos avanços nas tecnologias da informação e da migração do periódico impresso para o meio eletrônico, não há mudanças fundamentais na natureza das metodologias de gestão das revistas científicas.

A estrutura de um periódico científico (RAMACCIOTTI; TAVARES, 2009; BERNIUS, 2010), seja em formato impresso ou digital, vem se aprimorando de tal forma que, hoje, quando se ouve o termo periódico científico ou revista científica, pode-se visualizar uma capa, seguida de expediente, sumário, editorial, artigos e, no final, as normas para publicação. A estrutura de um periódico científico impresso, no Brasil, é fundamentada nas normas da Associação Brasileira de Normas Técnicas - (ABNT, 2003). Para periódicos, a norma de referência utilizada é a NBR 6021 Publicação Periódica Cientifica Impressa, onde são especificados os requisitos para apresentação dos elementos da estrutura de organização física de uma publicação periódica cientifica impressa.

O periódico científico digital, ou eletrônico, segue os mesmos critérios colocados para o impresso, a estrutura compreende: número do International Standard Serial Number (ISSN); titulo; capa (Layout); expediente; sumário; resumos e artigos em formato Portable Document Format (PDF). O periódico digital apresenta algumas características próprias (RAMACCIOTTI; TAVARES, 2009), dentre elas, a de produzir maior agilidade na disseminação de pesquisas e na preservação dessas informações. Outra característica importante é a democratização do acesso de qualquer ponto do mundo.

Consequentemente tem aumentado a preocupação dos profissionais (KRZYZANOWSKI; FERREIRA, 1998), que se interessam pela qualidade da informação. Pois, a qualidade do conteúdo de um periódico é que vai determinar a sua contribuição. Quando o pesquisador submete um artigo para avaliação, busca conferir credibilidade e disseminação ao seu trabalho. Neste sentido no Brasil o Qualis é um critério para escolher o meio de publicação. Para sua obtenção é preciso atender aos requisitos estabelecidos pela Coordenação de Aperfeiçoamento de Pessoal de Nível Superior (CAPES). O Sistema Qualis avalia anualmente os periódicos de diferentes áreas em categorias A (A1, A2), B (B1, B2, B3, B4) e C dentro dos âmbitos, nacional e internacional. 
Neste contexto, emerge a seguinte problemática: Quais são os critérios necessários e suficientes para serem tidos em conta na gestão da Revista Iberamericana de Engenharia Industrial (IJIE) segundo a percepção do decisor? O presente trabalho tem por objetivo identificar, organizar e mensurar os critérios necessários e suficientes para auxiliar o processo para ajudar a indexar a Revista Iberoamericana de Engenharia Industrial no portal de periódicos CAPES segundo a percepção da decisora. Tendo em vista o potencial da metodologia MCDA-C para construir conhecimento em ambientes complexos, a mesma será utilizada como instrumento de intervenção para evidenciar um processo para sua gestão. Espera-se ao final do trabalho ter-se construído um volume de conhecimento, na gestora, que lhe permita visualizar as conseqüências de suas decisões nos aspectos por ela considerados necessário ao processo de indexação do periódico.

\section{Referencial teórico}

\subsection{Periódicos científicos}

A divulgação do conhecimento científico (VALENTE; LUZI 2000; BERNIUS, 2010) por meio de publicações contribui para o desenvolvimento da sociedade. O periódico científico (DONG et al., 2006) tem sido objeto de muitos estudos, motivados pelo papel que representa na construção do conhecimento científico. Meadows (1999) traz uma perspectiva histórica dos periódicos científicos. Segundo o autor os primeiros periódicos científicos surgiram por iniciativas de sociedades científicas. No ano de 1665, na França, é publicado periódico Journal des Sçavants, com artigos relatos de experiências em áreas do conhecimento como física e anatomia e se autodenominava como o primeiro instrumento de divulgações periódicas de informações científicas. O segundo título do periódico a ser publicado foi o Philosophical Transactions ainda no ano de 1665 em Londres. Esta publicação era de responsabilidade da Royal Society of London, uma instituição que foi criada em 1662 com o patrocínio de Carlos II, e preocupavam-se com a coleta e posterior comunicação de informações que eram originárias de observações e pesquisas de seus membros.

O modelo de periódico científico (STUMPF, 1996) começou a se difundir por toda a Europa, aumentando o número de publicações e as disseminando. Estes periódicos, em sua maioria, estavam diretamente vinculados a instituições científicas e eram utilizados para divulgar as realizações de seus membros no campo da ciência. A publicação científica (MUELLER; PECEGUEIRO, 2000) tem como papel validar e consolidar o avanço da ciência, e a literatura científica permite o seu registro e o resgate histórico.

Dentre as maneiras de divulgar a ciência, seja pela forma oral e, perpassando pelas reuniões e congressos, destaca-se o periódico científico, em formato impresso ou eletrônico, como um veículo responsável pela legitimação formal da pesquisa científica. Quatro funções (MUELLER, 
1999) que comumente são conferidas ao periódico científico: estabelecimento da ciência "certificada", ou seja, do conhecimento que recebeu o apoio da comunidade científica; canal de comunicação entre os cientistas e de divulgação mais ampla da ciência; arquivo ou memória científica e registro da autoria da descoberta científica. Mesmo que com as transformações recentes nos meios de comunicação, essas funções não se alteraram.

Mas, as revistas precisam adequar-se e preservar os padrões da Ciência. Pino (2002) destaca a valorização de revistas científicas que autenticam os critérios de permanência contra o efêmero, de periodicidade contra o ocasional, de indexação contra a invisibilidade, da abrangência nacional (ou internacional) contra a local, da exogenia contra a endogenia.

Mueller (1999) coloca que para ser considerado de boa qualidade, um periódico precisa publicar bons artigos, manter sua periodicidade e ter fácil acesso. A junção de bons artigos, ou seja, as razões que motivam autores mais conceituados a escolherem um determinado periódico para mandar seu manuscrito, é decorrência da regularidade da publicação e facilidade de acesso por leitores interessados. Pois, um portfólio de artigos com qualidade, periodicidade regular e facilidade de acesso, facilita ao periódico a inclusão em bases de dados internacionais e aumentam a sua visibilidade.

A visibilidade aumenta as chances de citação. O financiamento torna-se acessível aos periódicos com boa reputação, que publicam bons artigos, indexados e citados. A boa reputação se mantém com o rigor da seleção do portfólio de artigos. O rigor da seleção só pode ser aplicado onde há boa afluência de artigos. Mas a boa afluência de artigos depende de todo o resto do processo. Assim, o periódico científico é o produto de um trabalho coletivo dos atores (editores, referees, autores) envolvidos no processo de publicação.

No entanto, as tecnologias digitais de informação e comunicação, especialmente a web causaram mudanças significativas nesse cenário. A comunicação por meio de periódicos Científicos eletrônicos (GRUSZYNSKI; GOLIN; CASTEDO, 2008) vem ampliando significativamente nos últimos anos. Conforme estudo realizado por Lawrence (2001) mostram que a circulação eletrônica dos artigos aumenta aproximadamente $336 \%$ as citações on-line em relação à mesma fonte impressa e referendam a busca pela visibilidade e pelo prestígio em um campo especializado e competitivo.

Com surgimento do Sistema Eletrônico de Editoração de Revistas (SEER), foi possível a construção e gerenciamento de todo processo de publicação periódica eletrônica. O SEER (INSTITUTO BRASILEIRO DE INFORMAÇÃO EM CIÊNCIA E TECNOLOGIA, IBCT, 2010) é um software desenvolvido para a construção e gestão de uma publicação periódica eletrônica. Esta ferramenta contempla ações essenciais à automação das atividades de editoração de periódicos científicos. O SEER foi traduzido e customizado pelo IBICT, baseado no software desenvolvido pelo Public Knowledge Project (Open Journal Systems) da Universidade British Columbia. 
A primeira vantagem vista pelos editores de títulos científicos on line, apresentados ainda com layout nos moldes das revistas impressas, foi a alteração na distribuição e visibilidade das edições. Não se trata apenas do uso da tecnologia digital a fim de otimizar o processo de edição, com o uso de softwares de editoração, troca de dados via e-mail ou disponibilização de forma eletrônica do conteúdo criado para ser impresso - entre tantos outros facilitadores, mas da utilização dessa tecnologia na criação de novos modelos de comunicação das informações científicas (GRUSZYNSKI, 2007; GRUSZYNSKI; GOLIN; CASTEDO, 2008).

Portanto, o modelo de comunicação científica on-line pressupõe o uso de ferramentas, estratégicas e metodologias e compreende a inclusão de: o uso de software aberto (ou livre), arquivos abertos, para interoperabilidade em nível global e disseminação ampla e irrestrita de resultados da pesquisa científica.

\subsection{Avaliação de desempenho}

A avaliação de desempenho (AD) tem emergido nas últimas décadas como um dos mais bem fundamentados processo de gestão. Múltiplas abordagens têm sido propostas (FLETCHER, 2001; YOKOMIZO, 2009; KLINE; SULSKY, 2009; ENSSLIN, 2009). Para efeito deste trabalho será utilizada a definição de Avaliação de Desempenho proposta pelo LabMCDA (Laboratório de Metodologias Multicritério em Apoio à Decisão da UFSC):

\footnotetext{
Avaliação de Desempenho é o processo de gestão utilizado para construir, fixar e disseminar conhecimentos por meio de processo que identifica, organiza, mensura e integra os aspectos do contexto julgados relevantes pelos decisores de um contexto específico, medindo em que grau é alcançado e gerando procedimento para melhorar o desempenho (ENSSLIN, 2009).
}

A definição proposta orientou o processo para a identificação das seis dimensões (lentes) utilizadas para a analise sistêmica da literatura: (Lacerda et al., 2010):

i.Singularidade: cada contexto é único e representado pelos valores e preferências do decisor, para o ambiente específico;

ii.Conhecimentos limitados: o (a) decisor (a) tem a necessidade de expandir seu entendimento das consequências da decisão;

iii.Entidade Social: oportunizar os stakeholders com interesses na decisão a submeterem e defenderem seus interesses na decisão;

iv.Recursividade da aprendizagem participativa: é a dinâmica recursiva do processo de aprendizagem das partes envolvidas, notadamente do decisor (a);

v.Princípios da mensuração: os modelos utilizados para ajudar a construir o conhecimento dos atores devem atender as propriedades das escalas ordinais, de intervalo, e de razão; e

vi.Legitimação e validação: é a transparência da participação, o reconhecimento da utilidade do 
conhecimento gerado e a cientificidade do processo de construção do conhecimento utilizado.

\subsection{Avaliação de periódicos científicos}

A avaliação de periódico científico é tema de pesquisa desde pelo menos 1960 (GRUSZYNSKI, 2007), envolvendo parâmetros para dimensionar a qualidade das informações registradas. O estudo realizado por Krzyzanowski e Ferreira (1998), que considera os periódicos científicos sob os aspectos de forma e mérito (desempenho do conteúdo), hoje serve como referencia para a CAPES, do Ministério da Educação (MEC) para a classificação das publicações.

O critério Qualis de avaliação é o conjunto de procedimentos utilizados pela Capes para estratificação da qualidade da produção intelectual dos programas de pós-graduação. Tal processo foi concebido para atender as necessidades específicas do sistema de avaliação e é baseado nas informações fornecidas por meio do aplicativo coleta de dados. Como resultado, disponibiliza-se uma lista com a classificação dos veículos utilizados pelos programas de pós-graduação para a divulgação da sua produção (CAPES, 2010).

Nos periódicos estrangeiros, utiliza-se o Fator de Impacto da base de dados Journal Citation Reports (JCR) do Institute for Scientific Information (ISI) ${ }^{1}$ para os níveis A e B, sendo nível A os periódicos com fator de impacto igual ou superior a 0,5 e nível $\mathrm{B}$ os periódicos com fator de impacto inferior a 0,5 . No caso de periódicos editados no exterior que não façam parte do JCR, a Comissão de Área analisará outras informações disponíveis, por exemplo, no sítio do periódico, para definir a respectiva classificação.

Portanto, destaca-se a importância do papel de um o modelo de avaliação de desempenho para destacar as características de forma do periódico, permitindo detectar aspectos técnicos que necessitam de ajustes.

\subsection{Processo de publicação de artigos científicos}

O processo de edição e publicação on-line compreende aspectos específicos vinculados ao suporte como disponibilidade de acesso, resgate das informações, critérios de interatividade e navegabilidade. Estes, por sua vez, devem seguir parâmetros compreendidos pelos periódicos impressos: apresentar política editorial, possuir conselho editorial, rigorosa revisão de qualidade (peer review), destinar-se a uma área especifica, manter edições regulares, apresentar ISSN, apresentar instruções aos autores, não ter caráter departamental, entre muitos outros fatores.

$\mathrm{Na}$ produção de um processo de publicação, ocorrem vários estágios, passando pela conclusão do manuscrito por parte dos autores, envio para um periódico cientifico, envio para referees, aceitação ou não por parte do periódico, até publicação final. Uma vez que os editores dos

\footnotetext{
${ }^{1}$ http://www.isinet.com/products/evaltools/jcr/
} 
periódicos recebem o manuscrito (DONG et al., 2006), tem-se o controle dos prazos, ou seja, fornecer informações sobre as datas em que o manuscrito foi recebido, revisado, aceito e publicado on-line (PATRA, 2006) ou impresso entre outros. Esta informação ajuda a analisar, estatisticamente, a velocidade de publicação da revista. Por outro lado, os autores, também, lidam com múltiplas tarefas na elaboração de um manuscrito. Esforços são direcionados em buscar um tema a ser trabalhado, expor o problema a ser discutida, revisão de literatura, preparação de instrumento de coleta de dados, análise de dados, conclusão, gastos com traduções entre tantas outras atividades presentes no processo.

Por meio da Internet a produção científica, realizada de forma tradicional (impresso), encontrou um processo de comunicação mais dinâmico, rápido e abrangente para disseminar a produção cientifica, proliferando, assim a criação de periódicos eletrônicos científicos. A submissão eletrônica até a atividade da redação final do manuscrito, certamente reduz o tempo necessário para o processo de publicação, se comparado com de periódicos impressos.

Toda comunicação entre autores, editores, editores da área e avaliadores é realizado no sistema, que emite e-mails para as partes interessadas. Desta forma, torna-se o recebimento das informações transmitidas entre os atores, resultando então numa crescente facilidade de comunicação entre os autores e uma maior agilidade e velocidade das publicações.

\subsection{Metodologia MCDA-C}

A metodologia MCDA-C é realizada em três fases de atividades integradas: a estruturação do contexto decisório; a construção de um processo para avaliação; e, a formulação de recomendações, conforme é visualizado na Figura 1.

Figura 1 - Fases da MCDA-C

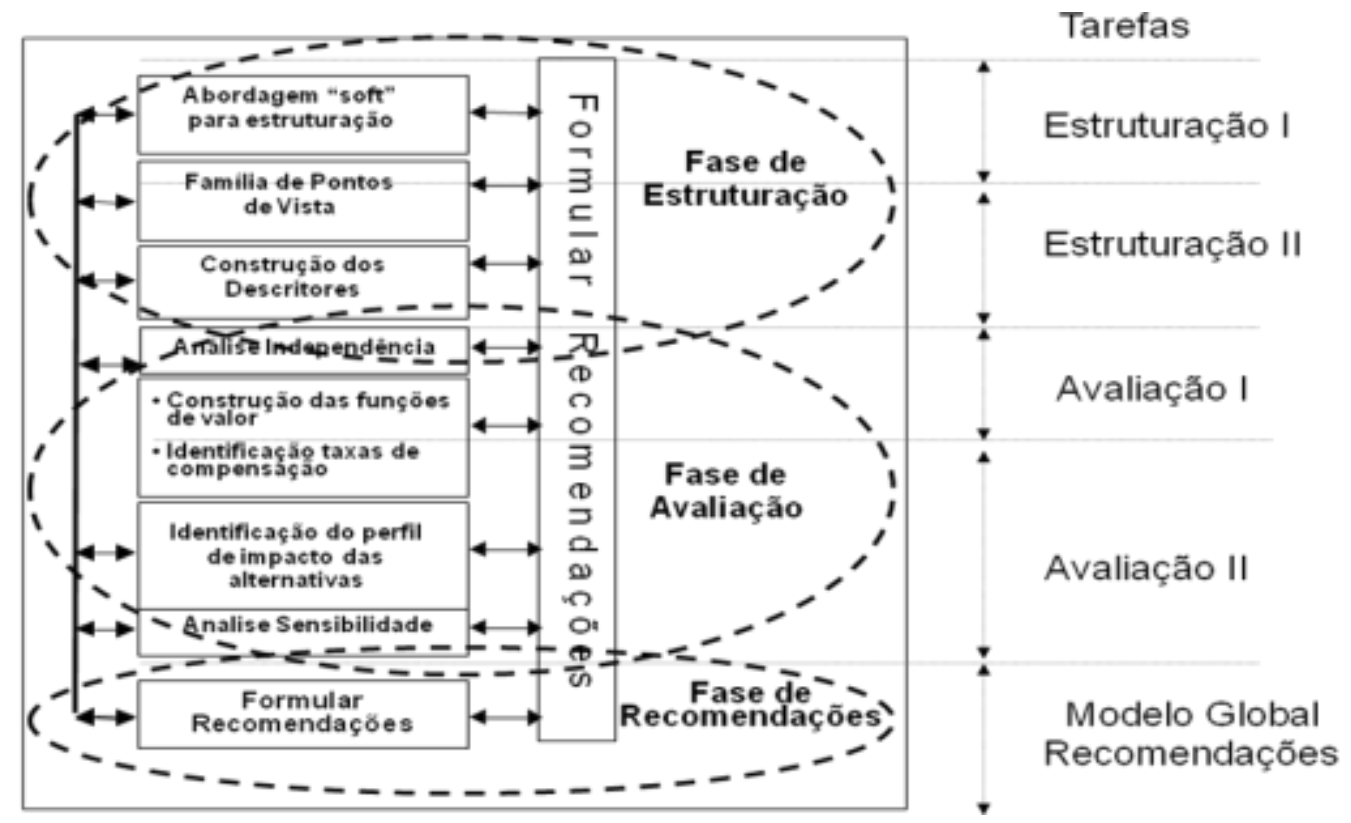

Fonte: ENSSLIN; MONTIBELLER; NORONHA (2001) 
A estruturação contribui ao identificar, organizar e mensurar ordinalmente as preocupações que o decisor considera necessárias e suficientes para a avaliação do contexto. A Avaliação é utilizada como um instrumento para melhorar o entendimento ao construir escalas cardinais e taxas de substituição para representar as preferências locais e globais. A etapa de Recomendações busca compreender as consequências de possíveis decisões nos critérios representativos das dimensões pelo decisor consideradas relevantes, bem como no contexto como um todo (ENSSLIN, et AL., 2010).

\section{Enquadramento metodológico}

Esta seção aborda os aspectos referentes ao enquadramento metodológico (Figura 2), os procedimentos para revisão da literatura; e o instrumento de intervenção selecionado para construir o modelo de avaliação dos critérios necessários e relevantes para indexar a Revista Iberoamericana de Engenharia Industrial no portal de periódicos Capes segundo a percepção do decisora.

Figura 2 - Aspectos metodológicos

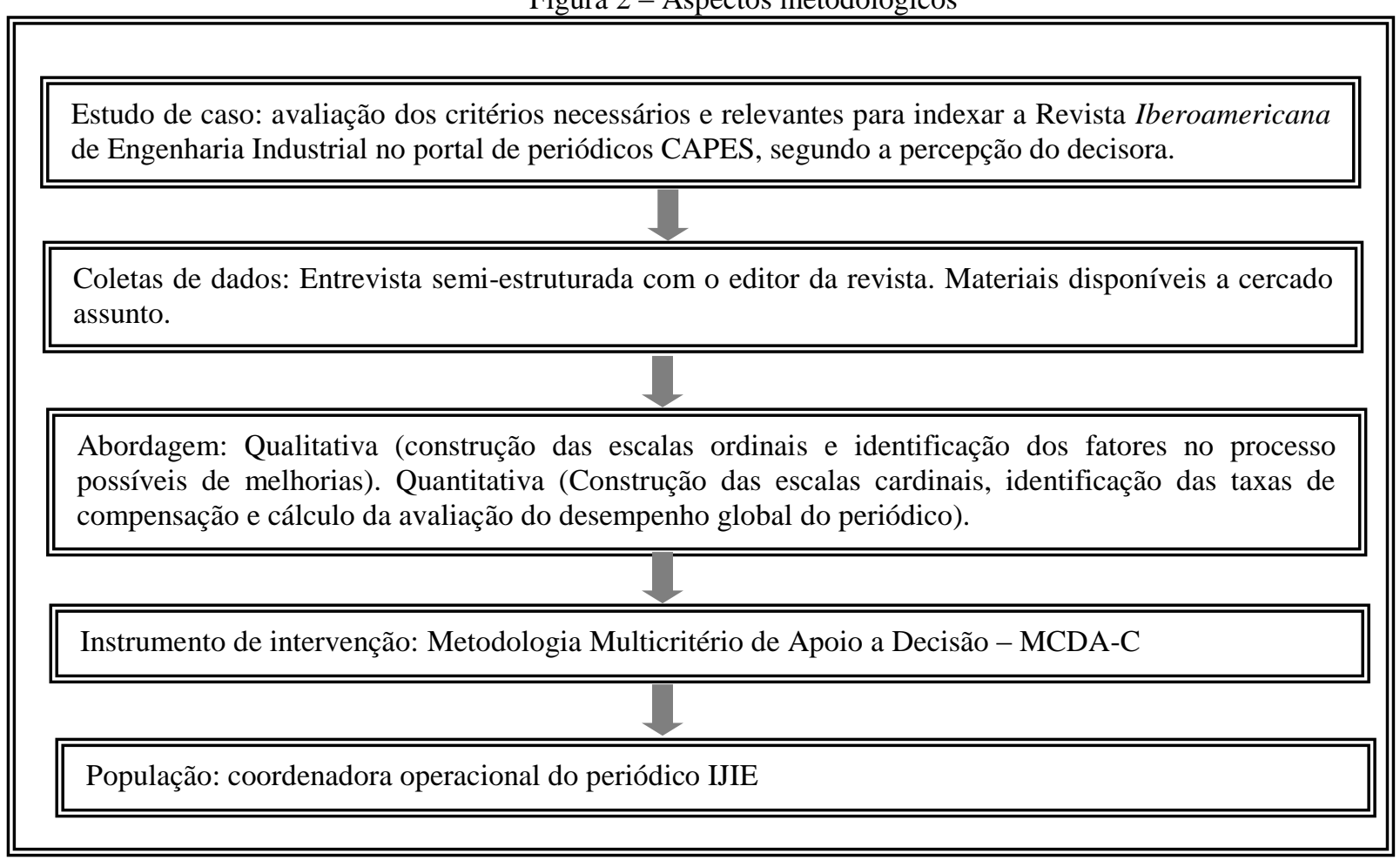

Fonte: Autoria própria (2010)

Na próxima seção apresentação o estudo de caso.

\section{Estudo de caso}

Nesta seção, apresentar-se-á a aplicação do instrumento de intervenção que será dividida em três fases: Estruturação do Contexto Decisório, Avaliação e Recomendações.

\subsection{Etapa de Estruturação do modelo}




\subsubsection{Contextualização, atores e rótulo}

O estudo de caso foi desenvolvido no periódico $\mathrm{IJIE}^{2}$, na atualidade encontra-se hospedado na incubadora de periódico UFSC (<http://periodicos.incubadora.ufsc.br/〉). O periódico tem como missão contribuir para a disseminação do conhecimento na área de Engenharia Industrial e áreas correlatas, mediante a divulgação de artigos científicos. Inicialmente fez-se a identificação dos envolvidos (atores) com poder de interferência no processo e aqueles com interesse nas decisões a serem tomadas, sejam eles: Decisor: Editora gerente/Coordenadora operacional do periódico representando o Comitê de Política Editorial. Intervenientes: Editor chefe, Conselho editorial e coordenadora executiva. Facilitadores: autores do trabalho. Agidos: autores, leitores, avaliadores e órgãos avaliadores.

Utilizando um processo de interação entre os facilitadores e o decisor, foi formado um Rótulo próximo às principais preocupações do decisor em relação ao problema. Isto é: Como elaborar um modelo para avaliar a Revista Iberoamericana de Engenharia Industrial tendo em vista sua gestão.

\subsubsection{Elementos Primários de Avaliação, Conceitos e Áreas de Preocupação (EPAS)}

Para o levantamento dos dados foram gravadas entrevistas com a decisora. Foi realizado um brainstorming, no qual se buscou que a decisora falasse a respeito do periódico IJIE. Essas preocupações ou aspectos relevantes foram denominados de Elementos Primários de Avaliação (EPA). Assim, foram identificados 78 Elementos Primários de Avaliação (EPAs) das entrevistas com o editor, relacionadas ao periódico IJIE. Os 8 primeiros estão ilustrados no Quadro 1.

\section{Quadro 1 - Os oito primeiros EPA identificados}

\begin{tabular}{|c|l|}
\hline EPA & \multicolumn{1}{|c|}{ Descrição } \\
\hline 1 & Estruturação dos Artigos \\
\hline 2 & Políticas editoriais do periódico \\
\hline 3 & Formatação do periódico \\
\hline 4 & Autores com tradição em linha de pesquisa \\
\hline 5 & Atualidade dos artigos \\
\hline 6 & Publicação de artigos dos membros do periódico \\
\hline 7 & Publicação de diferentes instituições \\
\hline 8 & Plágio \\
\hline
\end{tabular}

Com o intuito de melhorar o entendimento a respeito dos EPAs identificados pelo facilitador, em conversas com a decisora, para cada EPA foi elaborado um conceito para explicá-lo. O conceito é composto da seguinte forma: O polo presente (ou direção de preferência) referente ao objetivo que a decisora busca ao expressar a sua preocupação; e, O polo oposto psicológico, referente a uma situação (consequência) indesejada que a decisora busca evitar ou minimizar,

\footnotetext{
${ }^{2}$ Maiores detalhes sobre os periódicos estão disponíveis em: <http://periodicos.incubadora.ufsc.br/index.php/IJIE〉
} 
gerando melhor entendimento da motivação de seus objetivos. O Quadro 3 apresenta os oito primeiros EPA, seguidos do seu correspondente polo opostos psicológico, destaca-se que a reticência (...) deve ser lida como "é preferível a" ou "ao invés de" e corresponde ao oposto psicológico.

Quadro 2 - Os oito primeiros conceitos identificados

\begin{tabular}{|c|l|}
\hline Conceito & \multicolumn{1}{|c|}{ Descrição } \\
\hline C1 & $\begin{array}{l}\text { Estruturar o artigo de acordo com o padrão definido pelo periódico (...) Publicar artigos com padrões } \\
\text { diferentes na mesma edição }\end{array}$ \\
\hline C2 & $\begin{array}{l}\text { Assegurar que as normas definidas pela política editorial do periódico sejam seguidas em todas as } \\
\text { edições (...) Desestimular submissão }\end{array}$ \\
\hline C3 & Seguir formatação definida pelo periódico em todas as edições (...) Desestimular submissão \\
\hline C4 & Buscar trabalhos de autores com tradição em linha de pesquisa (...) Ser pouco conhecido \\
\hline C5 & Publicar artigos com temas atuais (...) Perder leitores \\
\hline C6 & Evitar a publicação de trabalhos de pessoas vinculadas ao periódico (...) Perder credibilidade \\
\hline C7 & $\begin{array}{l}\text { Assegurar edições com trabalhos publicados com o maior número possível de diferentes instituições } \\
\text { de ensino (...) Perder abrangência }\end{array}$ \\
\hline C8 & $\begin{array}{l}\text { Ter processo para identificar possíveis plágios de trabalhos submetidos (...) Ter problemas de ordem } \\
\text { legal e credibilidade. }\end{array}$ \\
\hline
\end{tabular}

Fonte: Autoria própria (2010)

Com todos os conceitos formados para as preocupações expressadas pela decisora, a próxima etapa consistiu na releitura (agrupamentos estruturados hierarquicamente e interligados com base em suas relações de influência) desses conceitos para identificar grandes Áreas de Preocupação (KEENEY, 1992; BANA E COSTA et al., 1999; ENSSLIN; DUTRA; ENSSLIN, 2000; ENSSLIN et al., 2010). Foram identificadas três grandes Áreas de Preocupação (Processo de Produção Editorial, Recursos Operacionais e Desenvolvimento do periódico), como mostra a Figura 3.

Figura 3 - Agrupamento dos conceitos com Áreas de Preocupação e PVF

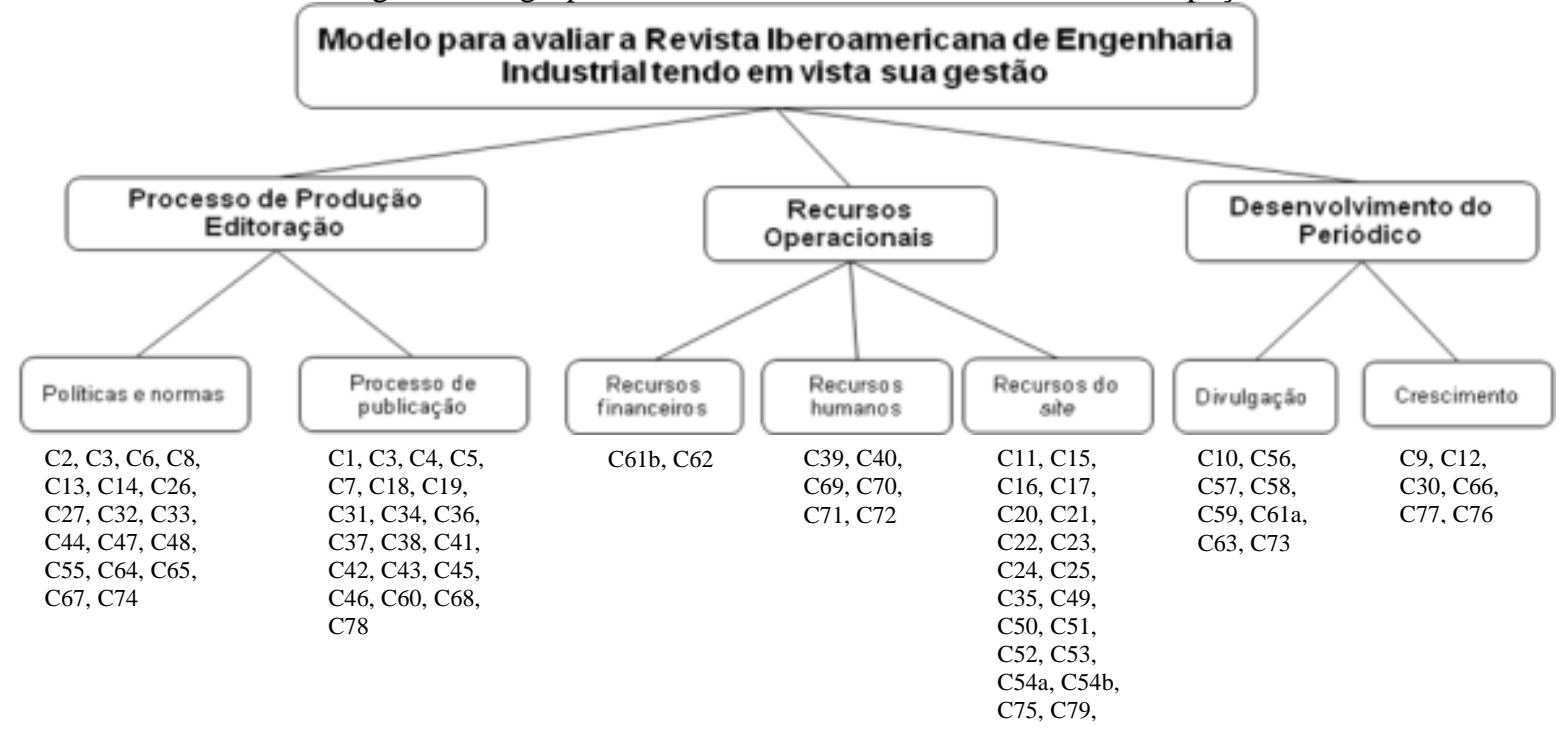

Fonte: Autoria própria (2010)

Processo de Produção Editorial: Refere-se aos aspectos considerados importantes pela decisora para o gerenciamento das atividades no periódico IJIE; Recursos Operacionais: Refere-se 
aos recursos considerados importantes pela decisora para o funcionamento do periódico; e Desenvolvimento do Periódico: Aspectos julgados importantes pela decisora para divulgar e propiciar a continuidade do periódico. Os nomes dados às áreas devem refletir da melhor forma possível a preocupação principal do decisor(a) ao expressar os conceitos pertencentes ao agrupamento. Salienta-se, que quem reflete o que é a área são os conceitos, e não o nome dado à mesma (ENSSLIN et al., 2010). A partir desses conceitos e seus agrupamentos foi possível construir uma árvore de Pontos de Vista (PV) (KEENEY, 1992). Assim, os PVFs constituem a realidade decisional (DUTRA, 1998) dos atores e esta realidade o norteará para a construção do seu modelo de avaliação.

Nessa estrutura, é possível considerar as três grandes áreas de interesse, que são explicadas pelos elementos a serem avaliados no periódico, sete Pontos de Vista Fundamentais (PVFs), foram apontados: Políticas e Normas, Processo de Publicação, Recursos Financeiros, Recursos humanos, Recursos do Site, Divulgação e Crescimento.

\subsubsection{Mapas Meios-Fins e Árvore de Pontos de Vista Elementares}

Nesta fase a metodologia MCDA-C expande o entendimento por meio da identificação das relações de hierarquia e das relações de influência entre os conceitos. Para tanto, vale-se de mapas de relações meios-fins (mapas cognitivos). Por meio das relações meio-fim (ENSSLIN; DUTRA; ENSSLIN, 2000) estabelecidas entre os conceitos, o mapa permite a transição dos conceitos mais abstratos para os conceitos passíveis de operacionalização. Destarte, que no processo de construção dos mapas, podem surgir novos conceitos (Tabela 1) não identificados anteriormente. Ao total foram identificados 139 conceitos.

Tabela - Totalidade de conceitos

\begin{tabular}{l|c}
\hline \multicolumn{1}{c|}{ Conceitos } & Quantidade \\
\hline Originais & 78 \\
Novos & 104 \\
Originais que permaneceram & 35 \\
Total Final & $\mathbf{1 3 9}$ \\
\hline Fonte: Autoria própria (2010)
\end{tabular}

A Figura 4 ilustra o mapa de meios-fins "Processo de Publicação" com seu cluster (mapas menores formados em função do foco de interesse do decisor) "atratividade do portfólio". Os demais clusters receberam a seguinte denominação: Submissão de artigos, Editoração dos artigos e “Gerenciamento de Prazos”. Os conceitos assinalados com asterisco (*) são que surgiram na construção deste mapa e os conceitos seguidos de letras são conceitos originais que foram substituídos por outros. O mesmo procedimento de construção dos mapas foi realizado para os outros seis PVF. 
Figura 4 - Mapa Meios-Fins para o Cluster "Atratividade do portfólio" e seus subclusters
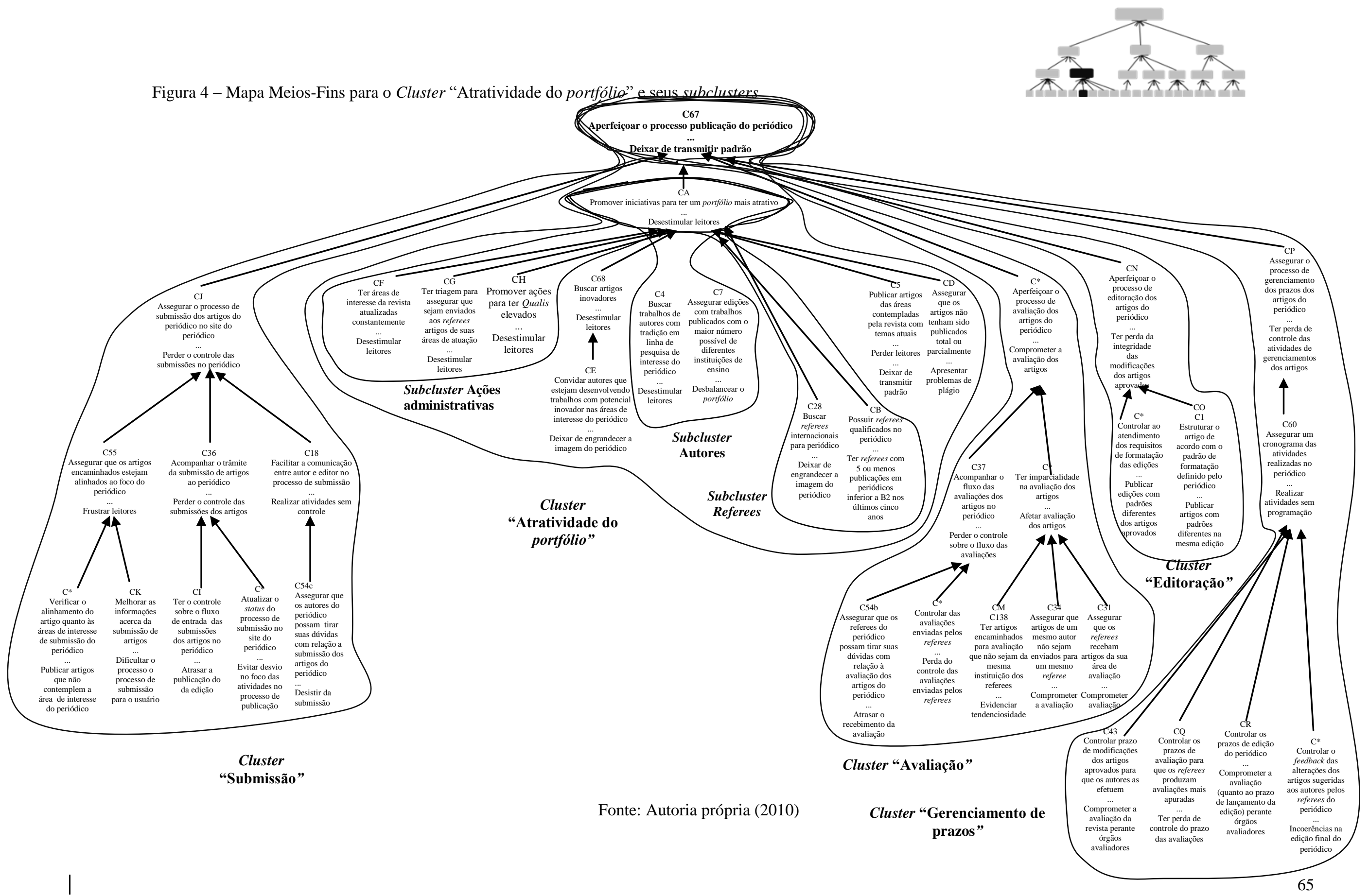
Construídos todos os mapas, para continuar o processo de construir o entendimento, exigese que a estrutura de relações de influência seja convertida em uma estrutura hierárquica de valor. Isto permite incorporar o entendimento dos julgamentos preferenciais de valor da decisora no modelo em construção (KEENEY, 1992; ENSSLIN et al. 2010).

\subsubsection{Estrutura hierárquica de valor e descritores}

A partir do mapa cognitivo os conceitos são agrupados em "clusters" e transportados para a estrutura hierárquica de valor. Cada cluster por sua vez subdivide-se em "subclusters". Tais subclusters devem obedecer às mesmas propriedades dos clusters iniciais e seu processo de transformação é equivalente ao utilizados para os PVFs e estes subcritérios são denominados Pontos de Vista Elementares (PVEs) (ENSSLIN, et al., 2010).

Este processo de decomposição continua até que se obtenha um PVE que represente uma propriedade do contexto e assim possa ser mensurado em forma objetiva, e não ambígua. A estrutura hierárquica então poderá em seus níveis inferior e superior ser mensurada conforme indica a Figura 5, gerada do mapa cognitivo da Figura 4, para o PVF "processo de publicação" com o correspondente PVE “atratividade do portfólio" e descritores.

A partir da estrutura hierárquica de valor, procedeu-se a construção dos descritores para expressar a forma proposta para mensurar aquilo que a decisora percebia como a propriedade que operacionaliza seu objetivo. O mesmo procedimento foi realizado para os demais PVF, para o modelo como um todo.

No total foram construídos 86 (desses, 11 de Políticas e Normas, 27 de Processo de Publicação, 4 de Recursos Financeiros, 9 de Recursos Humanos, 20 de Recursos do Site, 13 de Divulgação e 2 de Crescimento) descritores. Destaca-se que cada descritor recebeu um rótulo, por exemplo, "Percentual de artigos com autores multi-institucionais que participaram nas ultimas 4 edições" foi indicado pelo rótulo "Diversificar origem". 
Figura 5 - Estrutura hierárquica de valor com os descritores para o PVE “atratividade do portfólio" e escalas ordinais

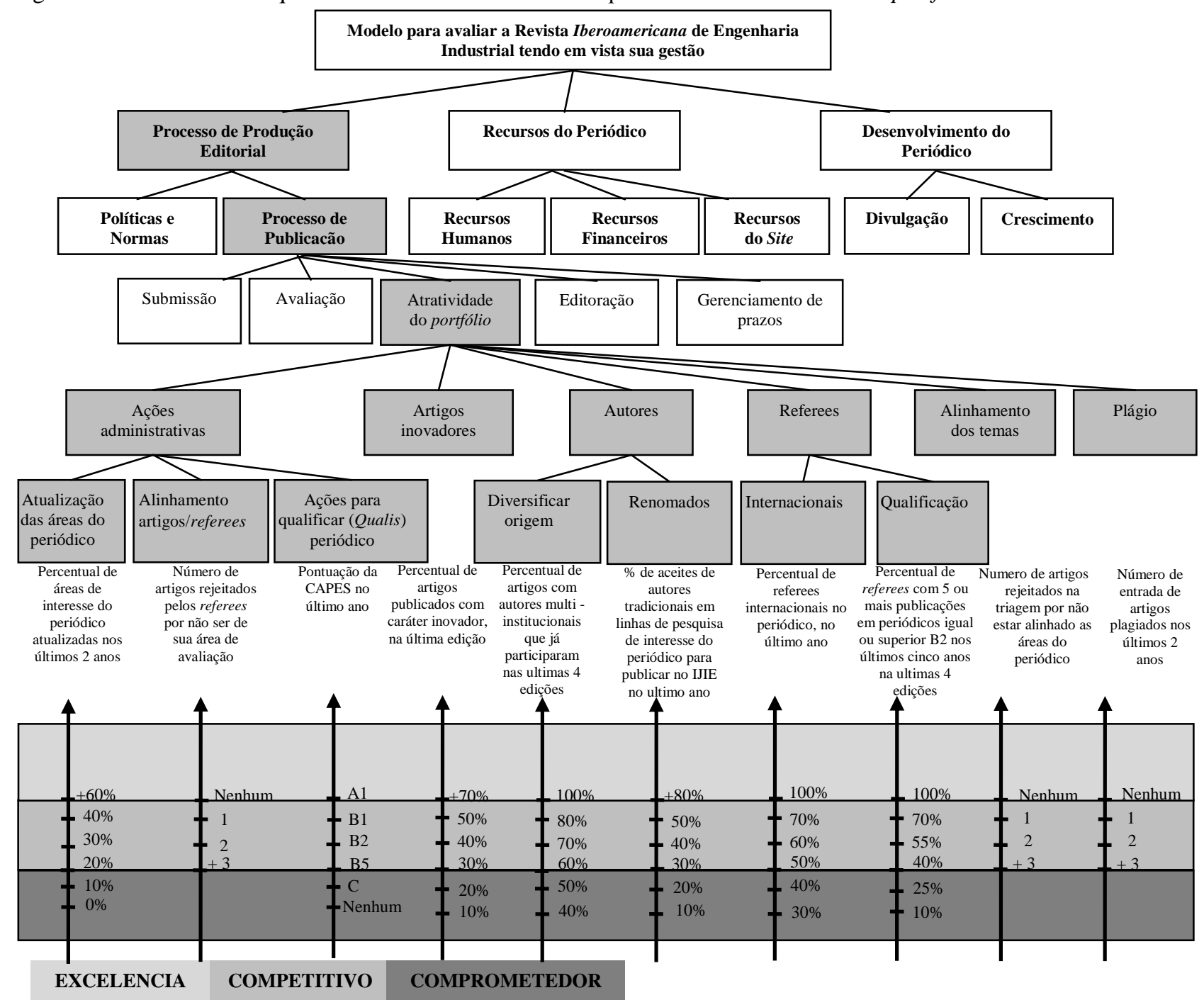

Fonte: Autoria própria (2010)

As escalas ordinais (ROY, 2005) foram estabelecidas em um processo interativo com o decisor. São identificados os Níveis de Referência (ou Âncoras), denominados Nível Bom, que representa o nível acima do qual o decisor julga a performance como excelente, e Nível Neutro, abaixo do qual o desempenho é comprometedor. Entre os dois pontos, o desempenho é competitivo.

\subsection{Etapa de avaliação}

Construídos os descritores (escalas ordinais), o próximo passo será determinar o grau de atratividade entre os níveis dos descritores, por meio da criação de uma função de valor, isto é, as escalas cardinais. Neste trabalho foi utilizado o método MACBETH (Measuring Attractiveness by a Cathegorical Based Evaluation Technique) cuja característica é transformar escalas ordinais em cardinais (BANA E COSTA; DE CORTE; VANSNICK, 2005) a partir de juízos absolutos sobre a diferença de atratividade entre níveis.

\subsubsection{Funções de valor}


A partir das informações de todos os PVE, com o uso do Software M-Macbeth construiu-se escalas cardinais que representem as preferências da decisora (Funções de Valor), com base em uma escala ordinal de sete categorias semânticas (BANA E COSTA; VANSNICK, 1995) propostas a priori ao decisor para cada intervalo do descritor. A Figura 6 apresenta o processo de transformação de uma escala ordinal para a função de valor (escala cardinal) para o descritor "artigos desalinhados".

Figura 6 - Transformação do Descritor “alinhamento dos temas” na Função de Valor utilizando o Método MACBETH

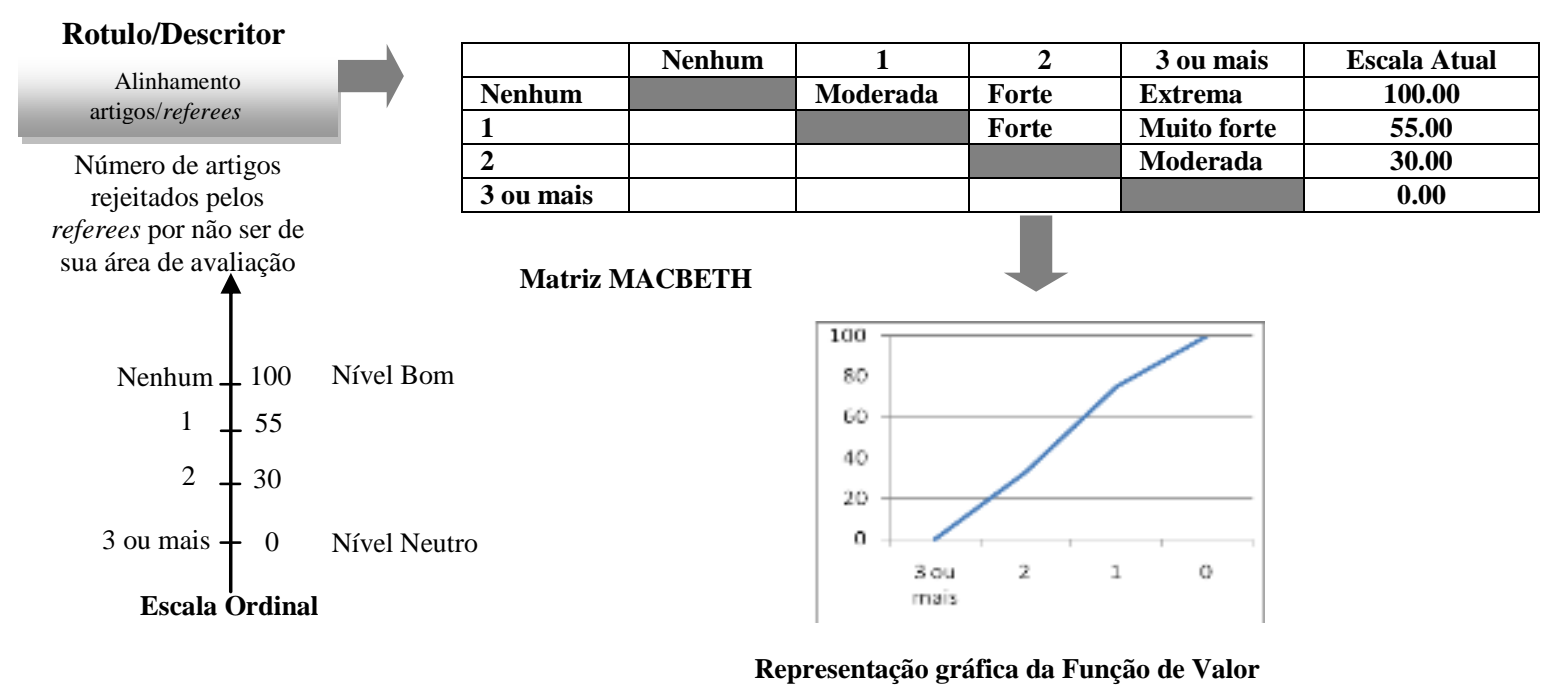

Fonte: Autoria própria (2010)

Os modelos construídos pela metodologia MCDA-C permitem explicitar a avaliação em forma numérica e/ou gráfica. Isto facilita a identificação e compreensão da intensidade dos pontos fortes e fracos das alternativas sendo avaliadas (LACERDA, ENSSLIN e ENSSLIN, 2010). A Figura 7 apresenta o conjunto de escalas cardinais construídas para o PVE "atratividade do portfólio". Em cada escala a esquerda está o descritor (escala ordinal) e à direita a função de valor (escala cardinal) correspondente. 
Figura 7 - Escalas cardinais para o PVE "atratividade do portfólio"

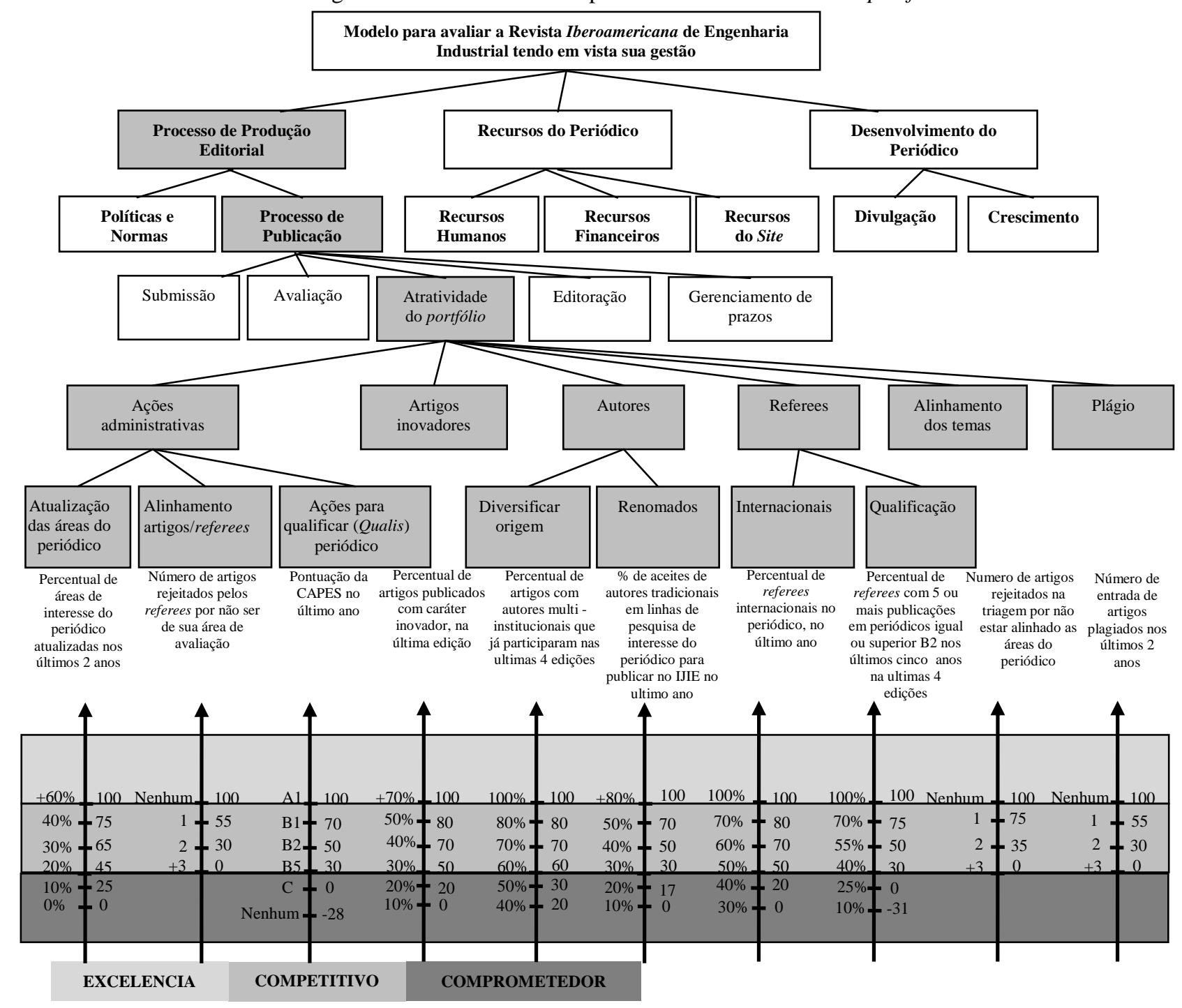

Fonte: Autoria própria (2010)

Assim, nesta etapa teve-se como objetivo ajudar a compreender a diferença de atratividade entre os níveis dos descritores. Para dar seguimento ao processo de construção do modelo, informações devem ser adicionadas para que se possam integrar as escalas cardinais.

\subsubsection{Taxas de Compensação (TC) ou de Substituição}

A construção das Taxas de Compensação é determinada seguindo as atividades:

a) Identificação de alternativas associadas;

b) Ordenamento das alternativas;

c) Construção das diferenças de atratividade das alternativas.

Para efeito deste trabalho será ilustrado o PV "Atratividade do portfólio", como pode ser visualizado na Figura 8. O método utilizado foi o de Comparação Par-a-Par (ENSSLIN et al., 2010) do MACBETH, pois não há necessidade de que o decisor expresse seus julgamentos de valor por meios numéricos, mas semânticos. O procedimento foi utilizado para determinar as taxas para os 
PVEs: aqui é mostrado a exemplo, Atualização das áreas do periódico, Alinhamento artigos/referees e Ações para qualificar (Qualis) periódico, segundo Figura 8.

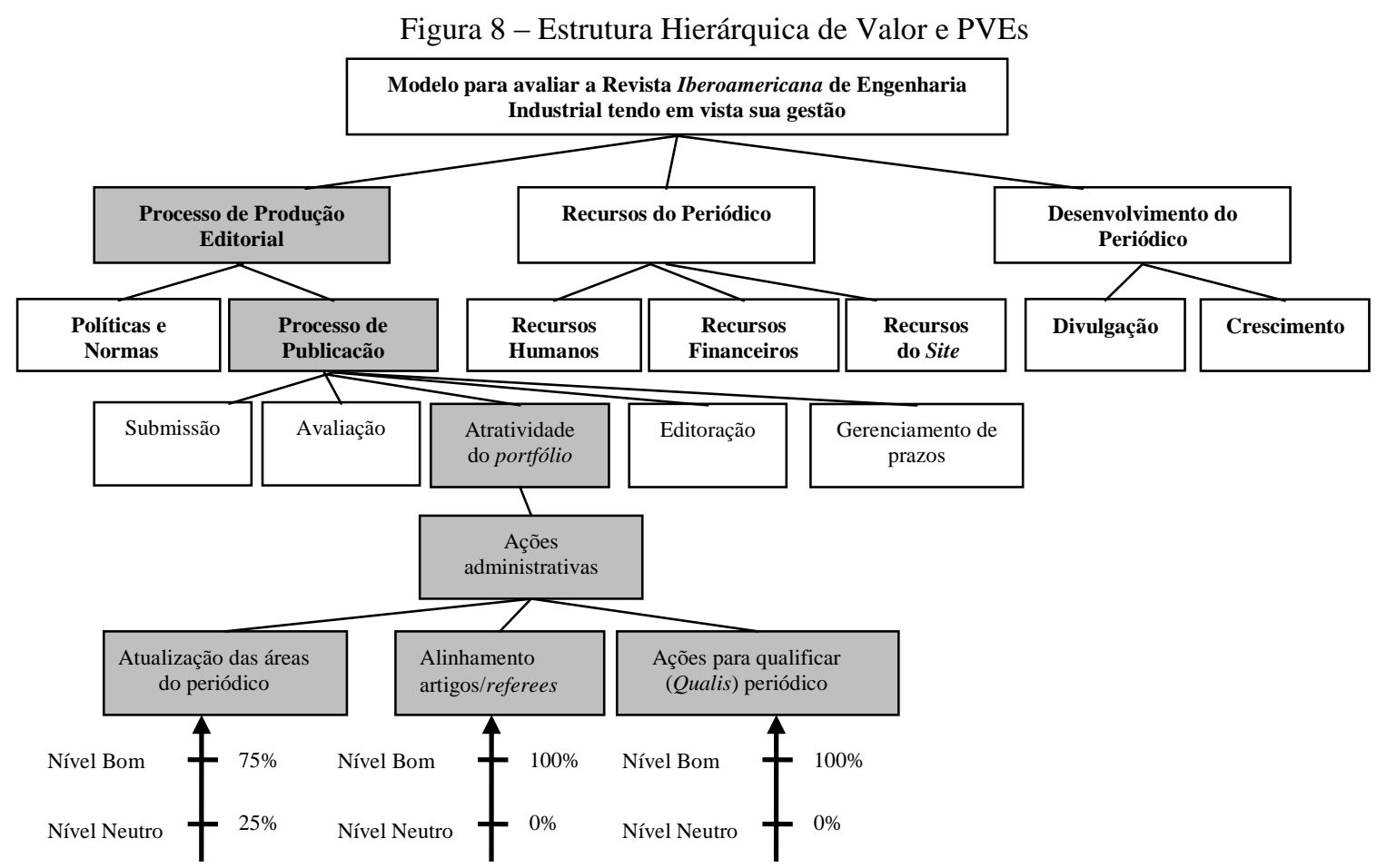

Fonte: Autoria própria (2010)

Primeiramente, é preciso criar ações potenciais (ENSSLIN et al., 2010) que representem a passagem do nível Neutro para o nível Bom, em cada um dos critérios que se quer determinar as Taxas de Compensação, assim como uma ação de referência com desempenho Neutro em todos os pontos de vista (Figura 9).

Figura 9 - Potenciais alternativas para determinar as taxas de compensação com a indicação dos seus níveis Bom e Neutro

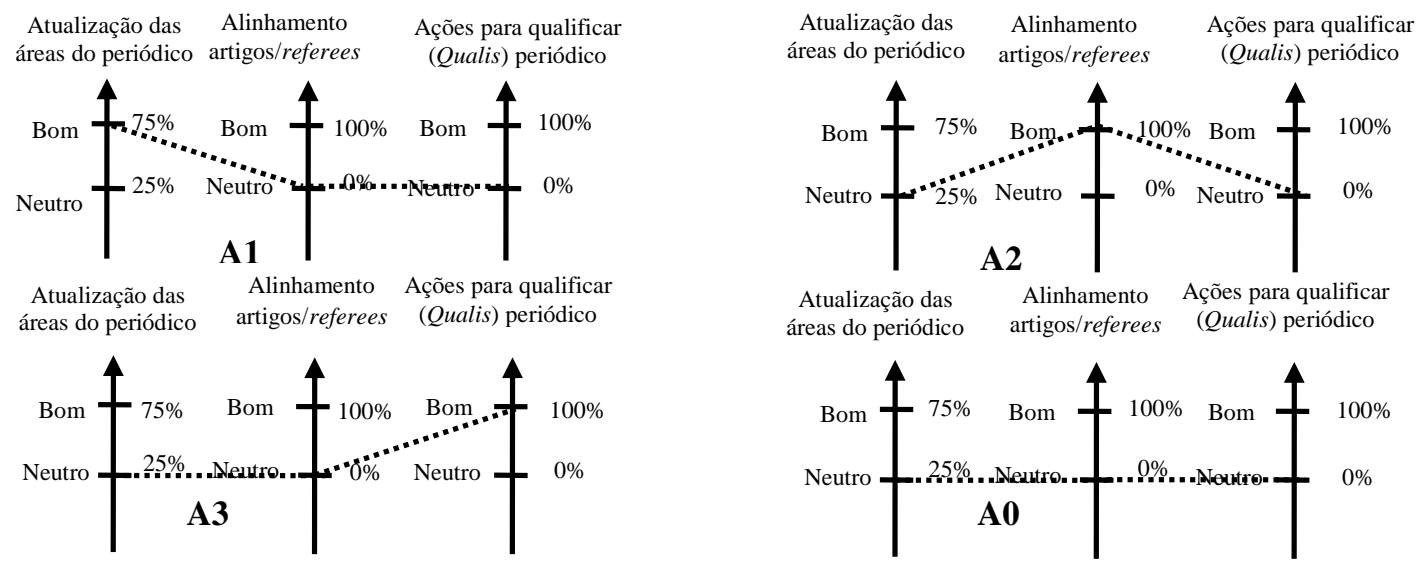

Fonte: Autoria própria (2010)

Para ordenar as alternativas foi utilizada a Matriz de Roberts. Esta consiste em comparar a preferência para cada elemento na linha $i$ em relação ao elemento na coluna $j$, atribuindo o valor 1 à preferida e 0 à outra. Ao final do procedimento tem-se a hierarquização das alternativas, onde 
ordem mostra a preferência do (a) decisor (a) de passar do nível Neutro para o nível Bom em cada PVE. A ilustração a Matriz de Roberts pode ser visualizada no Quadro 3.

Quadro 3 - Ilustração da Matriz de Roberts

\begin{tabular}{|c|c|c|c|c|c|c|}
\hline & A1 & A2 & A3 & A0 & Soma & Ordem \\
\hline A1 & & 0 & 0 & 1 & 1 & 3 \\
\hline A2 & 1 & & 0 & 1 & 2 & 2 \\
\hline A3 & 1 & 1 & & 1 & 3 & 1 \\
\hline A0 & 0 & 0 & 0 & & 0 & 0 \\
\hline
\end{tabular}

Fonte: Autoria própria (2010)

Realizadas a ordenação das alternativas o próximo passo é identificar a diferença de atratividade entre as ações agora ordenadas. Para sua realização mais uma vez recorreu-se ao Software M-Macbeth, o qual forneceu as respectivas taxas dos PVEs "Ações para qualificar (Qualis) periódico", “Alinhamento artigos/referees" e "Atualização das áreas do periódico”. Como ilustrado no Quadro 4 para o PVE- Ações Administrativas.

Quadro 4 - Taxas de Compensação para os PVEs

\begin{tabular}{|c|c|c|c|c|c|}
\hline & $\mathrm{A} 3$ & $\mathrm{~A} 2$ & $\mathrm{~A} 1$ & $\mathrm{~A} 0$ & Escala Atual \\
\hline $\mathrm{A} 3$ & & Fraca & Moderada & Muito Forte & $\mathbf{4 1 . 0 0}$ \\
\hline A2 & & & Fraca & Muito Forte & $\mathbf{3 4 . 0 0}$ \\
\hline A1 & & & & Muito Forte & $\mathbf{2 5 . 0 0}$ \\
\hline A0 & & & & & $\mathbf{0 . 0 0}$ \\
\hline
\end{tabular}

Fonte: Autoria própria (2010)

Procedimento semelhante foi realizado com todas as estruturas hierárquicas. Na Figura 10 mostra-se a Estrutura Hierárquica de Valor com as Taxas de Compensação do modelo construído, para os PVFs de acordo com os níveis de referência estabelecidos pela decisora. 
Figura 10 - Taxas de Compensação dos PVFs

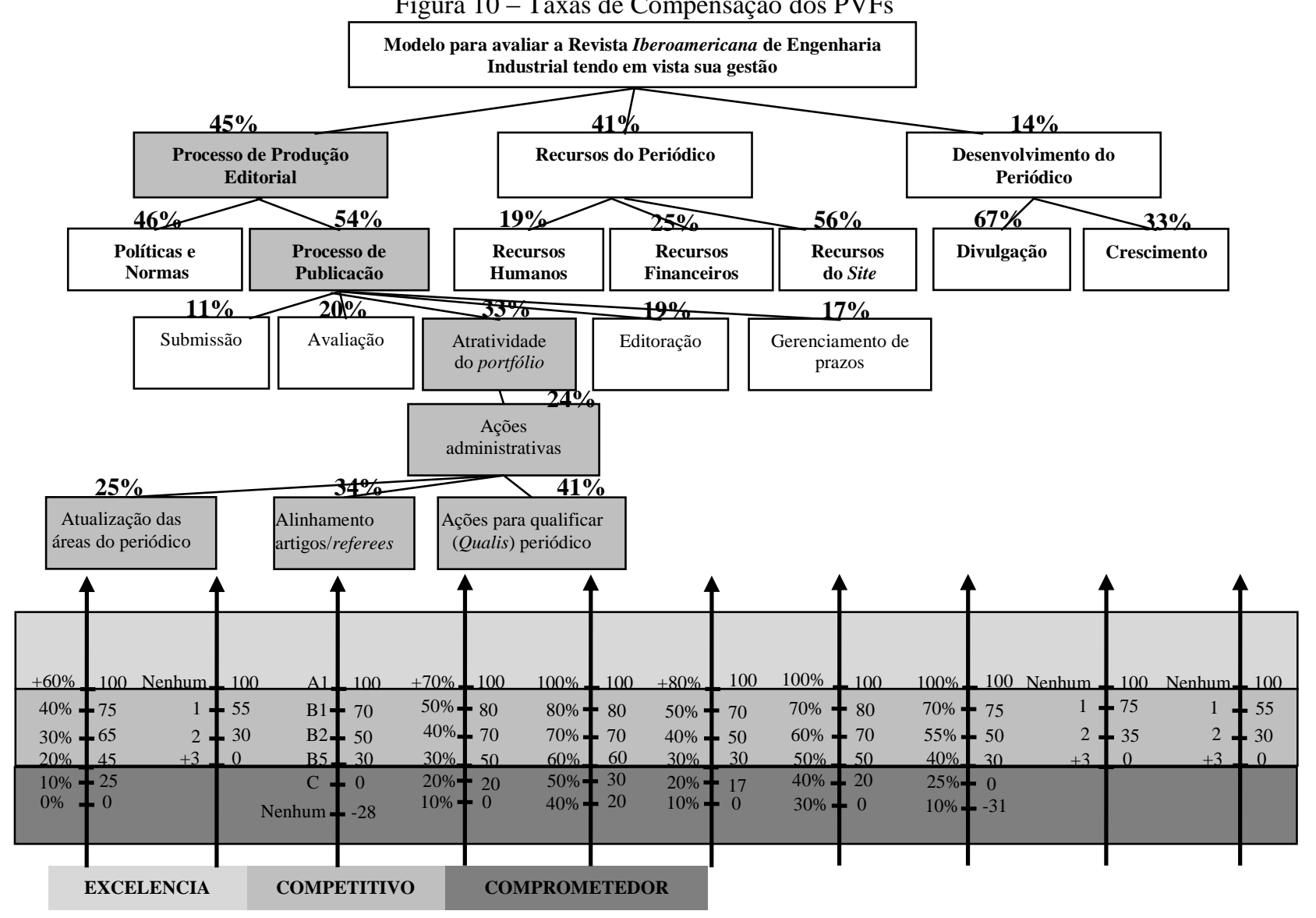

Fonte: Autoria própria (2010)

O mesmo procedimento foi realizado para a determinação das taxas para os todos os PVFs.

\subsection{Avaliação global e perfil de impacto da situação atual}

O Modelo global do MCDA-C é dado pela Equação 1. Ou seja, composto pela soma dos modelos de cada PVF.

$$
V(a)=\sum_{j=1}^{n} K_{J} * V_{j}\left[g_{j}(a)\right]
$$

Onde: $V(a)=$ Valor Global da alternativa $\mathrm{a}$;

$\mathrm{g}=$ descritor do $\mathrm{PV}_{\mathrm{J}}$

$g_{j}(a)=$ Impacto da alternativa a no descritor $g_{j}$;

$\mathrm{V}_{\mathrm{j}}\left(\mathrm{g}_{\mathrm{j}}(\mathrm{a})\right)=$ Valor parcial da alternativa a no $\mathrm{PV}_{\mathrm{j}} ; \mathrm{e}$

$\mathrm{K}_{\mathrm{j}}=$ Taxa de Compensação do $\mathrm{PVF}_{\mathrm{j}}$

Assim, temos a Equação do Modelo Global (Equação 2) para "Avaliar a Revista Iberoamericana de Engenharia Industrial tendo em vista sua gestão”.

$\mathrm{V}_{(\mathrm{a})}=0,2025 * \mathrm{~V}_{\text {Politicas e Normas }}(\mathrm{a})+0,243 * \mathrm{~V}_{\text {Processo de Publicação }}(\mathrm{a})+0,0779 * \mathrm{~V}_{\text {Recursos Humanos }}(\mathrm{a})+0,1025 * \mathrm{~V}_{\text {Recursos }}$
Financeiros
$(\mathrm{a})+0,2296 * \mathrm{~V}_{\text {Recursos do Site }}(\mathrm{a})+0,0938 * \mathrm{~V}_{\text {Divulgação }}(\mathrm{a})+0,0462 * \mathrm{~V}_{\text {Crescimento }}(\mathrm{a})$ 
As constantes da Equação 2 (0,2025; 0,243; 0,0779; 0,1025; 0,2296; 0,0938 e 0,0462) são resultado do produto das taxas, ou seja, o valor 0,2025 corresponde a $0,46 * 0,45$, e assim sucessivamente. Para cada PVF, apresenta-se um modelo na forma genérica (Equação 2). Na Equação 3, tem-se a ilustração para o PVF "Processo de Publicação".

$\mathrm{V}_{\text {Processo de publicação }}(\mathrm{a})=0,11 * \mathrm{~V}_{\text {Submissão }}(\mathrm{a})+0,20 * \mathrm{~V}_{\text {Avaliação }}(\mathrm{a})+0,33 * \mathrm{~V}_{\text {Atratividade do portfólio }}(\mathrm{a})+0,19 * \mathrm{~V}_{\text {Editoração }}(\mathrm{a})$

$+0,17 * V_{\text {Gerenciamento de prazos }}(\mathrm{a})$

Abrindo a Equação 3 em "atratividade do portfólio" temos a Equação 4.

$\mathrm{V}_{\text {Atratividade do portfólio }}(\mathrm{a})=0,24 * \mathrm{~V}_{\text {Ações administrativas }}(\mathrm{a})+0,03 * \mathrm{~V}_{\text {Artigos inovadores }}(\mathrm{a})+\mathrm{V}_{\text {Autores }}(\mathrm{a})+0,23 * \mathrm{~V}_{\text {Referees }}(\mathrm{a})$

$+0,14 * \mathrm{~V}_{\text {Alinhamento dos temas }}(\mathrm{a})+0,15 * \mathrm{~V}_{\text {Plágio }}(\mathrm{a})$

Por sua vez, as Equação 5, 6 e 7 mostram que:

$\mathrm{V}_{\text {Ações administrativas }}(\mathrm{a})=0,44 *$ vAtualização das áreas do periódico $(\mathrm{a})+0,36 * \mathrm{~V}_{\text {Alinhamento artigos/referees }}(\mathrm{a})+0,20 * \mathrm{~V}_{\text {Ações para qualificar }}(\mathbf{5})$ (Qualis) periódico (a)

$\mathrm{V}_{\text {Autores }}(\mathrm{a})=0,05 * \mathrm{~V}_{\text {Diversificar origem }}(\mathrm{a})+0,10 * \mathrm{~V}_{\text {Renomados }}(\mathrm{a})$

$V_{\text {Referees }}(\mathrm{a})=0,19 * \mathrm{~V}_{\text {Internacionais }}(\mathrm{a})+0,09 * \mathrm{~V}_{\text {Qualificação }}(\mathrm{a})$

Na Figura 11 pode ser visualizado a Estrutura Hierárquica de Valor para o PVF "Processo de Publicação" com as Taxas de Substituição apenas para o PVE "atratividade do portfólio" foi calculado para os demais PVEs assim como para os demais foi utilizado o mesmo procedimento. 
Figura 11 - Taxas de Compensação do PVE "Atratividade do portfólio"

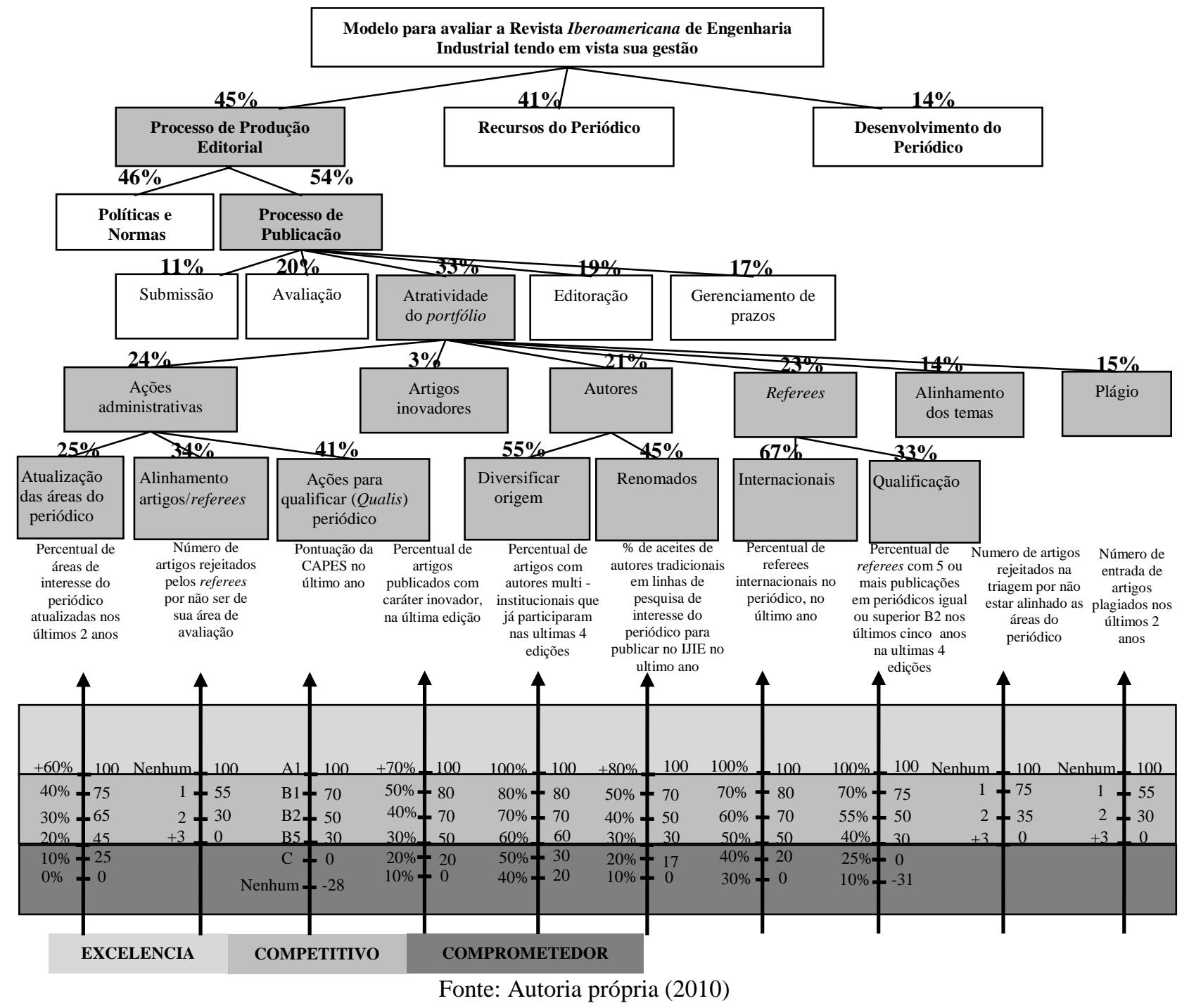

Realizando o mesmo processo para os demais PVFs, tem-se a construção do modelo global. Neste momento, pode-se utilizar o modelo para apoiar o processo de gestão (ENSSLIN, et al., 2010), o que é realizado com o suporte do modelo global de avaliação. Com o auxilio do Modelo Global, a decisora identificou a pontuação e o perfil do periódico, como é demonstrado na Figura 12. 
Figura 12 - Estrutura hierárquica de valor e o comportamento gráfico Status quo do periódico IJIE

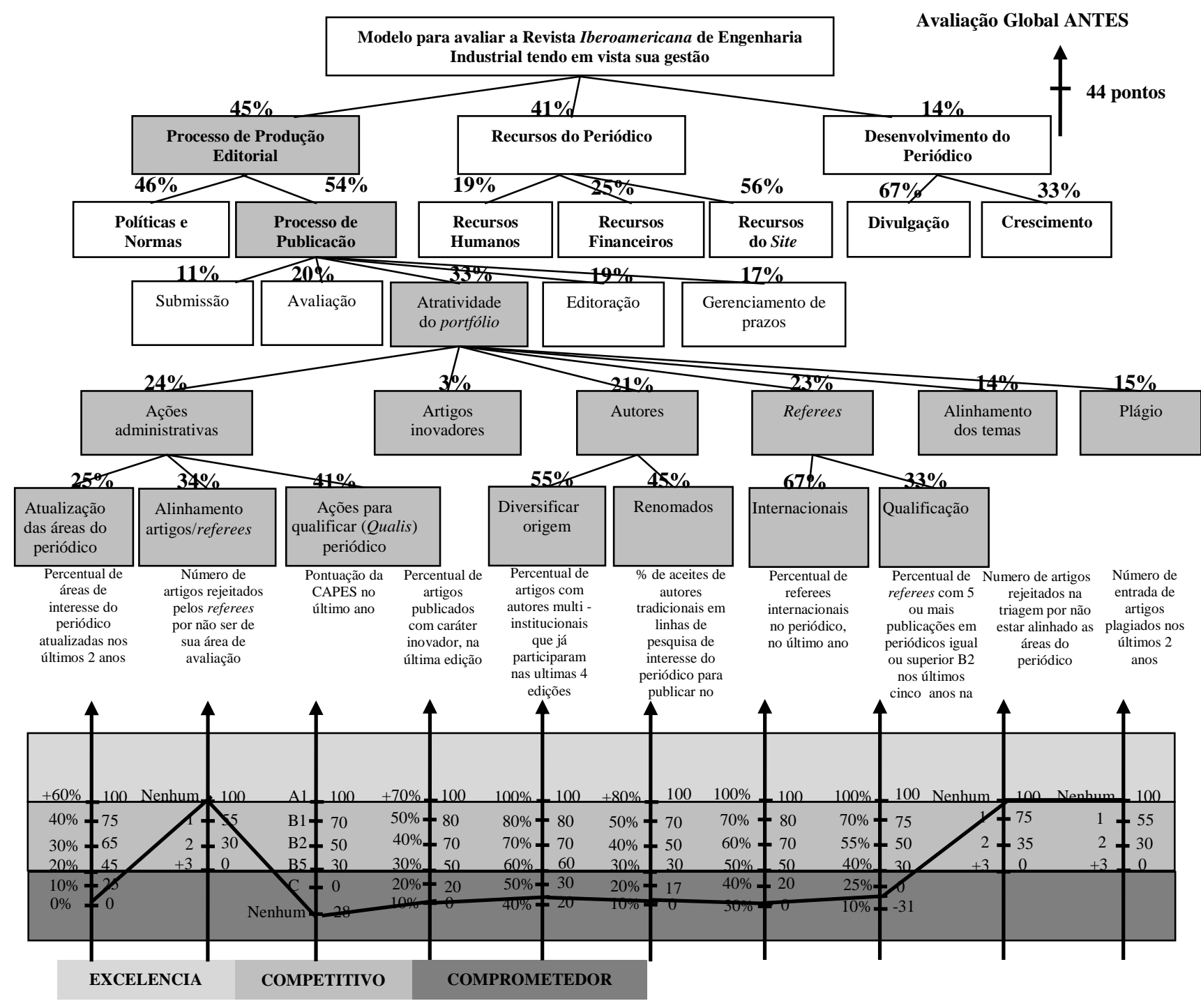

Fonte: Autoria própria (2010)

Como pode ser observado na Figura 12 o periódico apresenta dois PVFs com desempenho comprometedor, "Recursos Financeiros" e "Crescimento". O perfil de desempenho das ações permitiu visualizar gráfica e numericamente as consequências das ações nos aspectos julgados pela decisora como estratégicos para a avaliação do contexto. Perante todo processo gerado, o editor do IJIE poderá optar por ações de melhorias para aspectos do processo que não estão de acordo com o desejado em termos produção editorial e, consequentemente, constatar o impacto dessa modificação de forma local e global.

\subsection{Recomendações}

A etapa de Recomendações é quando o conhecimento construído é utilizado para buscar ações que permitam melhorar a performance global do contexto avaliado. Segundo Ensslin et al., (2010) esta etapa na metodologia MCDA-C tem por função auxiliar o (a) decisor (a) para ajudá-lo (a) a identificar formas para melhorar o desempenho do elemento que está sendo avaliado, de tal modo a 
entender as consequências destas ações nos objetivos estratégicos do decisor, caso venham a ser implementadas. Esta etapa começa identificando os PVFs os quais se deseja aperfeiçoar a performance. Para a presente analise será utilizado o PVF "Processo de publicação". Como pode ser observado na Figura 13, o PVE “Ações para qualificar (Qualis) periódico” apresenta o desempenho em níveis mais comprometedores, sendo este, o principal candidato ao aperfeiçoamento.

Figura 13 - Perfil do Status quo se implemantadas ações de aperfeiçoamento no PVE "Atratividade do portfólio"

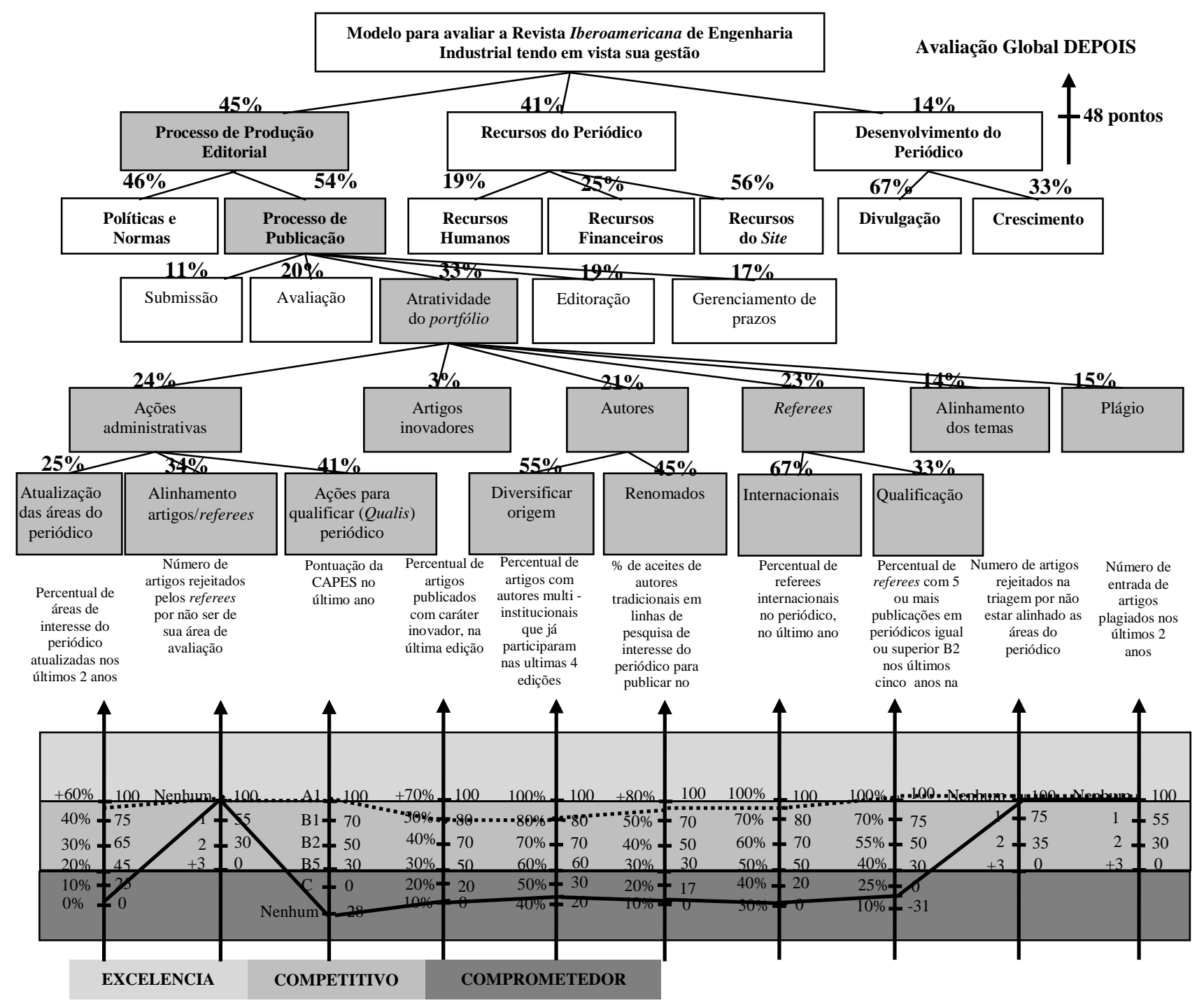

Perfil Status quo

Fonte: Autoria própria (2010)

Algumas ações de melhoria foram identificadas, para o PVF "Processo de publicação" de forma geral, como mostra o Quadro 5 de acordo com a percepção dos atores que as identificaram.

Quadro 5 - Sugestões de melhorias

\begin{tabular}{|c|l|}
\hline Indicador & \multicolumn{2}{|c|}{ Ações } \\
\hline Ações para qualificar (Qualis) periódico & Adaptar as políticas e normas direcionadas aos critérios da Capes \\
\hline Autores renomados & Monitorar o mercado de periódicos e verificar autores \\
\hline
\end{tabular}




\begin{tabular}{|c|l|}
\hline & $\begin{array}{l}\text { internacionais que estejam desenvolvendo trabalhos no foco do } \\
\text { periódico e convidá-los para publicar. }\end{array}$ \\
\hline Referees internacionais & $\begin{array}{l}\text { Buscar em sites de Instituições de ensino internacionais } \\
\text { profissionais qualificados com titulação de doutor e convida-los, } \\
\text { formalmente, para tornarem-se e referees do periódico. }\end{array}$ \\
\hline Atualização das áreas do periódico & $\begin{array}{l}\text { Verificar constantemente os temas desenvolvidos no mercado de } \\
\text { periódicos, situados em Engenharias III, conforme critérios de } \\
\text { qualificação Capes. }\end{array}$ \\
\hline
\end{tabular}

Fonte: Autoria própria (2010)

Desta forma, a metodologia MCDA-C foi trabalhada em suas três fases: Estruturação, Avaliação e Recomendações; mantendo seus pressupostos construtivistas.

\section{Considerações finais}

O desenvolvimento da ciência influencia de forma direta a comunicação científica, de certa forma podendo refletir na circulação do conhecimento originado por esta atividade sendo inerente à sua própria concepção. O processo publicação de um periódico científico eletrônico exige que se garanta a qualidade dos conteúdos publicados tendo como referência os valores das diferentes áreas da ciência, dentro de um sistema de comunicação que está em constante modificação.

O objetivo geral da pesquisa consistiu em construir um modelo para construir conhecimento sobre os critérios necessários para ajudar a indexar a Revista Iberoamericana de Engenharia Industrial no portal de periódicos CAPES segundo a percepção do decisora neste estudo é ilustrado o ponto de vista processo de "Publicação do periódico" para evidenciar como o conhecimento construído pode ajudar a gestora a identificar oportunidades de aperfeiçoamento e monitorar a gestão da revista para qualificá-la para ser indexada no portal da CAPES. Este objetivo foi alcançado por meio do uso da MCDA-C, o modelo desenvolvido permitiu identificar três áreas de preocupação (Processo de Produção Editorial, Recursos operacionais e Desenvolvimento do periódico) e sete Pontos de Vista Fundamentais (PVF), foram apontados: Políticas e Normas, Processo de Publicação, Recursos Financeiros, Recursos humanos, Recursos do Site, Divulgação e Crescimento.

Para esse PVFs foram destacados os seguintes PVEs: Políticas de Submissão, Políticas de Regulamentação, Políticas de Crescimento, Políticas de Avaliação, Atratividade do portfólio, Avaliação, Editoração, Gerenciamento de Prazos. A partir daí foram construídos os 86 descritores propostos, foram construídas as respectivas escalas ordinais.

A partir de então, a metodologia MCDA-C mostrou como gerar ações de aperfeiçoamento suas consequências ao mostrar que a pontuação da mesma no PVF "Processo de publicação" mudaria de 54 pontos para 76 pontos se as ações de aperfeiçoamento recomendadas fosse implementadas, enquanto o valor global passaria de 44 pontos para 48 pontos. O PVE “Ações para qualificar (Qualis) periódico" apresentou o desempenho em níveis mais comprometedores, sendo este, o principal candidato ao aperfeiçoamento. 
O modelo construído no estudo de caso foi legitimado pelo decisor em cada etapa de sua construção, e com sua utilização, a decisora conta com um instrumento que oportuniza a melhoria da gestão do periódico IJIE. Em meio às contribuições do trabalho, destaca-se a demonstração da potencialidade da metodologia MCDA-C para expandir o conhecimento do decisor quanto as conseqüências do contexto e suas possíveis ações de aperfeiçoamento em seus valores e preferências.

Como limitação da pesquisa, ressalta-se o caráter de personalização do modelo, não recomendando a replicação do modelo em outros contextos, uma vez que o modelo foi construído segundo os valores e preferências de uma decisora específica. Quanto ao processo proposto pela metodologia MCDA-C, as limitações apontadas recaem sobre o comprometimento da participação do decisor e o elevado tempo que o processo demanda.

Portanto, todo este processo de busca de aperfeiçoamento do periódico IJIE resultou pela oportunidade de ter-se construído conhecimento sobre o contexto que possibilitou: identificar o que é importante; organizar; mensurar ordinalmente; mensurar cardinalmente; integrar os critérios e medir cardinalmente a atratividade Global e ter processo para monitorar e aperfeiçoar em forma original e inovadora.

\begin{abstract}
The expanse of new titles journals in different fields of knowledge has been a concern of professionals that care about the quality of scientific information. Are authors, editors, publishers, indexing services, documentation centers, libraries and, in particular, researchers (information users). The scientific production, traditionally do through print journals, found an Internet communication process more dynamic, rapid and comprehensive. This aims to build knowledge on relevant and necessary criteria Coordination of Improvement of Higher Education Personnel (CAPES) to index the Journal of Industrial Engineering at the Iberoamericana journal portal in perception of the decider. Using a qualitative-quantitative approach. The intervention instrument used was the MCDA-C. Methodology enabled the construction of knowledge about context that in order to identify that is important, organize, measure ordinal; measure cardinally; integrate the criteria and measure the attractiveness cardinally Global. Thus, process provided by the model and enabling the manager to understand the consequences of these actions.
\end{abstract}

Key-words: scientific journals; performance assessment; MCDA-C, decision making.

\title{
Referências
}

ASSOCIAÇÃO BRASILEIRA DE NORMAS TÉCNICAS. NBR6021/ 1994: Informação e Documentação Publicação periódica cientifica impressa - Apresentação. Rio de Janeiro: ABNT, 2003.

BANA E COSTA, C. A.; VANSNICK, J. C. Uma nova abordagem ao problema da construção de uma função de valor cardinal: MACBETH. Investigação Operacional, v. 15, p. 15-35, 1995

cross ${ }^{\text {ref }}$

BANA E COSTA, C. A.; ENSSLIN, L.; CORRÊA, É. C.; VANSNICK, J. C. Decision support systems in action: integrated application in a multicriteria decision aid process. European Journal of Operational Research, v. 113, p. 315-335, 1999. 
BANA E COSTA, C.A.; DE CORTE, J. M.; VANSNICK, J. C. On the mathematical foundations of macbeth. In: Multicriteria Decision Analysis: state of the art survey [edited by J. F. Greco and S.M. Ehrgott], Springer Verlag, Boston, Dordrecht, London, 409-442, 2005.

BERNIUS, S. The impact of open access on the management of scientific knowledge. Online Information Review, v. 34, n. 4, p. 583-603, 2010.

cross ret

CAPES. Coordenação de Aperfeiçoamento de Pessoal de Nível Superior. Qualis Periódicos. Disponível em: <http// http://www.capes.gov.br/avaliacao/qualis>. Acesso em: 15 out. 2010.

DONG, P.; LOH, M.; MONDRY, A. Publication lag in biomedical journals varies due to the periodical's publishing model. Scientometrics, v. 69, n. 2, p. 271-286, 2006.

cross ref

DUTRA, A. Elaboração de um sistema de avaliação de desempenho dos recursos humanos da secretaria de estado da administração - SEA à luz da Metodologia Multicritério de Apoio a Decisão. Dissertação (Programa de Pós-graduação em Engenharia de Produção), Universidade Federal de Santa Catarina, UFSC, Florianópolis, SC, 1998.

ENSSLIN, L.; DUTRA, A.; ENSSLIN, S. R. MCDA: a construtivist approach to the management of human resources at a governmental agency. International Transactions in Operational Research, v. 7, p. 79-100, 2000.

cross ref

ENSSlin, L.; MONTIBELleR, G. N.; NORONHA, S. M. Apoio à Decisão: Metodologias para Estruturação de Problemas e Avaliação Multicritério de Alternativas. Insular, Florianópolis, 2001.

ENSSLIN, S. R. et al.. Uma metodologia multicritério (MCDA-C) para apoiar o gerenciamento do capital intelectual organizacional. Revista de Administração Mackenzie - RAM, v. 9, n. 7, p. 136-163, 2008.

ENSSLIN, L. Processo decisório e aspectos cognitivos. Simpósio de Pesquisa Operacional e Logística da Marinha, 07, Anais..., 2009.

ENSSLIN, L.; ENSSLIN, S. R. Avaliação de desempenho. Notas de aula, 2010.

ENSSLIN, L. et al.. Avaliação do desempenho de empresas terceirizadas com o uso da metodologia multicritério de apoio à decisão - construtivista. Pesquisa Operacional, v. 30, n. 1, p.125-152, Janeiro a Abril de 2010.

FLECTHER, C. Performance appraisal and management: the development research agenda. Journal of Occupational Organizational Psychology, v. 74, p. 473-487, 2001.

cross ${ }^{\text {ref }}$

GRUSZYNSKI, A. C. A edição de periódicos científicos eletrônicos: desafios para a visibilidade da ciência na Web. INTERCOM - Sociedade Brasileira de Estudos Interdisciplinares da Comunicação, XXX Congresso Brasileiro de Ciências da Comunicação - Anais..., 2007.

GRUSZYNSKI, A. C.; GOLIN, C. CASTEDO, R. Produção editorial e comunicação científica: uma proposta para edição de revistas científicas. Revista da Associação Nacional dos Programas de Pós-Graduação em Comunicação - E-compós, Brasília, v. 11, n. 2, maio/ago. 2008.

IBCT. INSTITUTO BRASILEIRO DE INFORMAÇÃO EM CIÊNCIA E TECNOLOGIA. Sistema Eletrônico de Editoração de Revistas, 2010. Disponível em: <http://www.ibict.br/secao.php?cat=seer>. Acesso em: 01 Nov. 2010.

KEENEY, R. L. Value-focused thinking: a path to creative decision making. Harvard University Press, London, 1992.

KLINE, Theresa, J.B.; SULSKY, L. M. Measurement and Assessment Issues in Performance Appraisal. Canadian Psycology, v. 50, n. 3, p. 161-171, 2009.

cross ref

KRZYZANOWSKI, R. F.; FERREIRA, M. C. G. Avaliação de Periódicos Científicos e Técnicos Brasileiros. Ciência da Informação, Brasília, DF, v. 27, n. 2, p. 165-175, maio./ago. 1998. 
LACERDA, R. T.; ENSSLIN, L.; ENSSLIN, S. R. Um estudo de caso sobre gerenciamento de portfólio de projetos e apoio à decisão multicritério. Revista Gestão Industrial, v. 6, n. 01, p. 01-28, 2010.

LACERDA, R. T. O.; ENSSLIN, L.; ENSSLIN, S. R. A performance measurement view of it project management. The International Journal of Productivity and Performance Management, v. 60, n. 2, 2011.

cross ref

LAWRENCE, Steve. Free online availability substantially increases a paper's impact. Nature Debate. Disponível em: <http://www.nature.com/nature/debates/e-access/ Articles/lawrence.html>. Acesso em: 31 set. 2010.

LÉVY, P. As tecnologias da inteligência: o futuro do pensamento na era da informática. Ed. 34. Rio de Janeiro, 1995.

MEADOWS, A. J. A comunicação científica. Brasília, DF: Briquet de Lemos, 1999. 268 p.

MOGHADDAM, G. G.; MOBALLEGHI, M. How do we measure the use of scientific journals? a note on research methodologies. Scientometrics, v. 76, n. 1, p. 125-133, 2008.

cross ref

MUELLER, S. P. M. O círculo vicioso que prende os periódicos nacionais. Revista de Ciência da Informação, dez/1999.

MUELleR, S. P. M.; PECEGUEIRO, C. M. P. de A. O periódico Ciência da Informação na década de 90: um retrato da área refletido em seus artigos. Ciência da Informação, mai/ago. 2001, v. 30, n. 2, p.47-63.

PATRA, C. Introducing e-journal services: an experience. The Electronic Library, v. 24, n. 6, p. 820-831, 2006. cross ret

PAVAN, C.; STUMPF, I. R. C. Revistas Brasileiras de Ciência da Informação: procedimentos de avaliação pelos pares. VIII ENANCIB - Encontro Nacional de Pesquisa em Ciência da Informação, 08, 2007, Salvador, Bahia, Anais..., Salvador: ENANCIB, 2007.

PINO, I. Editoração de revistas científicas no campo da Educação. In: BUENO, B. O.; AQUINO, J. G.; CARVALHO, M. P.(Orgs.). Política de publicação científica em educação no Brasil hoje. São Paulo: FEUSP, 2002.110p.

RAMACCIOTTI, A. S.; TAVARES, E. S. Criação e desenvolvimento de revista científica de acesso aberto em formato digital - o caso da Revista PAIDÉI@. Revista Cientifica de Educação a Distância, v. 2, n. 2, p. 1-13, dez. 2009.

ROY, B. Paradigms and challenges, multiple criteria decision analysis - state of the art survey. In: Multicriteria Decision Analysis: state of the art survey [edited by J.F. Greco and S.M. Ehrgott], Springer Verlag, Boston, Dordrecht, London, 03-24, 2005.

SALAS, Ch. Sugerencias para mejorar la calidad de las revistas científicas chilenas: una aplicación en las ciencias forestales con Bosque. Bosque, v. 1, n. 29, p. 3-10, 2008.

SOUZA, J. V. de. Processo para avaliar periódicos científicos: proposta e ilustração para a Revista Contemporânea de Contabilidade. Dissertação (Programa de Pós-graduação e Contabilidade), Universidade Federal de Santa Catarina, UFSC, Florianópolis, 2010.

STUMPF, I. R. C. Passado e futuro das revistas científicas. Ciência da Informação, Brasília, DF, v. 25, n. 3, p. 383386, set./dez. 1996.

VALENTE, A.; LUZI, D. Different contexts in electronic communication: some remarks on the communicability of scientific knowledge. Journal of Documentation, v. 56, n. 3, May, p. 299-311, 2000.

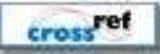

YOKOMIZO, C. A. Avaliação de desempenho organizacional: um estudo exploratório em empresas brasileiras de desenvolvimento de software. 175f. Dissertação. (Programa de Pós-Graduação em Administração) - Universidade de São Paulo, Faculdade de Economia, Administração e Contabilidade, São Paulo, 2009. 


\section{Dados dos autores:}

Nome completo: Nara Medianeira Stefano, MSc

Filiação institucional: Universidade Federal de Santa Catarina (UFSC)

Departamento: Programa de Pós-Graduação em Engenharia da Produção

Função ou cargo ocupado: Doutoranda

Endereço completo para correspondência (bairro, cidade, estado, país e CEP): Campus Universitário - Florianópolis - SC - CP 476 - CEP 88010-970.

Telefones para contato: +55 (48) 37217065 ou (48) 96280129

e-mail: stefano.nara@gmail.com

Nome completo: Juliane Vieira de Souza, MSc

Filiação institucional: Universidade Federal de Santa Catarina (UFSC)

Departamento: Programa de Pós-Graduação em Engenharia da Produção

Função ou cargo ocupado: Doutoranda

Endereço completo para correspondência (bairro, cidade, estado, país e CEP): Campus Universitário - Florianópolis - SC - CP 476 - CEP 88010-970.

Telefones para contato: (48) 84127778

e-mail: juliane.vieiradesouza@gmail.com

Nome completo: Fabrício Kurman Merlin

Filiação institucional: Universidade Federal de Santa Catarina (UFSC)

Departamento: Programa de Pós-Graduação em Engenharia da Produção

Função ou cargo ocupado: Mestrando

Endereço completo para correspondência (bairro, cidade, estado, país e CEP): Campus Universitário - Florianópolis - SC - CP 476 - CEP 88010-970.

Telefones para contato: (48) 91621060

e-mail: merlin.fabricio@gmail.com

Nome completo: Leonardo Ensslin, Ph.D.

Filiação institucional: Universidade Federal de Santa Catarina (UFSC)

Departamento: Programa de Pós-Graduação em Engenharia da Produção

Função ou cargo ocupado: Professor Titular

Endereço completo para correspondência (bairro, cidade, estado, país e CEP): Campus Universitário - Florianópolis - SC - CP 476 - CEP 88010-970. 
Telefones para contato: (48) 3234-5515 ou (48) 9911-9374

e-mail: leonardoensslin@gmail.com

Nome completo: Sandra Rolim Ensslin, Dra

Filiação institucional: Universidade Federal de Santa Catarina (UFSC)

Departamento: Programa de Pós-Graduação em Engenharia da Produção

Função ou cargo ocupado: Professora Adjunta

Endereço completo para correspondência (bairro, cidade, estado, país e CEP): Campus Universitário - Florianópolis - SC - CP 476 - CEP 88010-970.

Telefones para contato: (48) 3234-5515 ou (48) 9911-9374

e-mail: sensslin@gmail.com

Enviado em: 16/03/2011

Aprovado em: 12/12/2011 